Running head: ADMINISTRATORS' PERCEPTIONS OF TEACHER EFFECTIVENESS

\title{
ADMINISTRATORS' PERCEPTIONS OF TEACHER EFFECTIVENESS IN RURAL NORTHWEST MISSOURI SECONDARY PUBLIC SCHOOLS
}

\author{
A Dissertation presented to \\ the Faculty of the Graduate School \\ at the University of Missouri-Columbia \\ In Partial Fulfillment \\ of the Requirements for the Degree \\ Doctor of Education \\ by \\ SARAH A. BARMANN-SMITH \\ Dr. Carole Edmonds, Dissertation Supervisor \\ May 2019
}


ADMINISTRATORS' PERCEPTIONS OF TEACHER EFFECTIVENESS

The undersigned, appointed by the dean of the Graduate School, have examined the

dissertation entitled

ADMINISTRATORS' PERCEPTIONS OF TEACHER EFFECTIVENESS IN RURAL

NORTHWEST MISSOURI SECONDARY PUBLIC SCHOOLS

presented by Sarah A. Barmann-Smith,

a candidate for the degree of doctor of education,

and hereby certify that, in their opinion, it is worthy of acceptance.

Dr. Jennee Barnes-Gregory

Dr. Carole Edmonds

Dr. Victoria Seeger

Dr. Timothy Wall 


\section{ADMINISTRATORS’'PERCEPTIONS OF TEACHER EFFECTIVENESS}

\section{DEDICATION}

Business strategist Tony Robbins stressed, “Don't limit your challenges; challenge your limits.” As I entered the MU doctoral program I decided to take on a new endeavor and challenge myself to continue to grow and learn while becoming better and following in the footsteps of many people I admire.

To my husband, Nick: Thank you for always loving me and having full faith in me. You have been such a motivator, supporter, and encourager through this process and in all things. Thank you for the countless days and nights that you took on the extra responsibilities as I worked long hours away from home to fulfill this accomplishment. You have been so great to push me to dream big and have helped me to achieve more than I thought I could.

To my children Viola and Camden: Thank you for being my why. I love that I can display grit, work ethic, and determination in pursuit of a goal and model what I hope will be characteristics that you will assume in all things you strive to do in your life. Never let anyone tell you "It can't be done."

To my parents: Thank you for raising me to be the strong-willed, caring, determined woman I am today. Without the foundation and guidance you established while raising me I would not be the leader I am today. Thank you for showing me how to sacrifice and put others first and the value in being an educator. I take great pride in being a fourth-generation educator.

Finally, I would like to dedicate this dissertation to the administrators and teachers who I have been blessed to work with who make an impact in the lives of students on a daily basis. They understand the opportunities and challenges faced in rural 
ADMINISTRATORS' PERCEPTIONS OF TEACHER EFFECTIVENESS

education. And to the all of the students who we work to help achieve their dreams;

remember, you should never be limited because of your zip code. 


\section{ADMINISTRATORS’ PERCEPTIONS OF TEACHER EFFECTIVENESS}

\section{ACKNOWLEDGEMENTS}

A special recognition to Dr. Carole Edmonds. I am fortunate and blessed to be your among last cohort to have the opportunity to receive your advisement and feedback along this process. Your support and guidance is unwavering and much appreciated. Thank you to Dr. Tim Wall who has always charged me to think deeply, consider possibilities, and explore to my potential. To Dr. John Rinehart who believed in me, gave me a chance, and always encouraged me to do my best. To Dr. Erin Oligschleager whose friendship and teamwork is invaluable in the contribution to who I am today. To the members of Cohort $\mathrm{X}$, our experiences- though trying at times- will remain some of the best learning experiences I have had. Finally, to my Fort Family and Warriors- thank you for always believing in me and supporting me. You are my tribe. 
ADMINISTRATORS' PERCEPTIONS OF TEACHER EFFECTIVENESS

TABLE OF CONTENTS

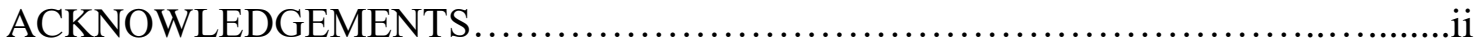

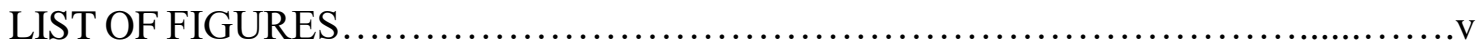

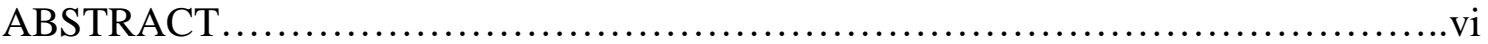

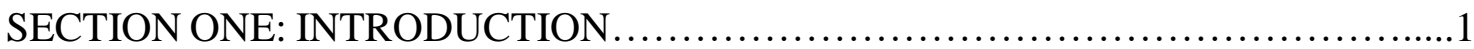

Background of the Study

Statement of the Problem

Purpose of the Study

Research Question

Conceptual Framework

Design of the Study

Limitations, Delimitations, and Assumptions

Definitions of Key Terms

Significance of the Study

Summary

SECTION TWO: PRACTITIONER SETTING FOR THE STUDY

Introduction for this Section

Background

History of the Organization

Organizational Analysis

Leadership Analysis

Implications for Research in the Practitioner Setting

Summary

SECTION THREE: SCHOLARLY REVIEW FOR THE STUDY

Introduction for this section

Conceptual Framework

Effective Teaching

Administrators' Role

Rural School Setting

Summary

SECTION FOUR: CONTRIBUTION TO PRACTICE

Contribution to Practice 
Type of Documents

Rationale for this Contribution Type

Outline of Proposed Contents

Presentation

SECTION FIVE: CONTRIBUTION TO SCHOLARSHIP

Target Journal

Rationale for this Target

Outline of Proposed Contents

Plan for Submission

SECTION SIX: SCHOLARLY PRACTITIONER REFLECTION

Influence of Dissertation on Educational Leadership

Influence of Dissertation Process on Scholarship

Conclusion

\section{APPENDIX}

A. Missouri Teacher Standards............................................. 105

B. Survey, Interview, and Focus Group Questions..............................109

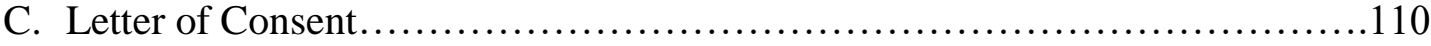

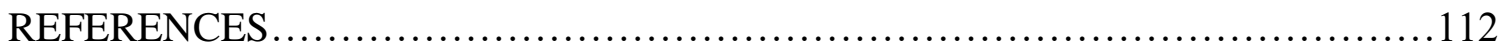

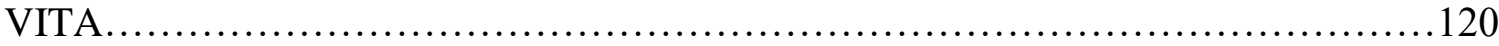


ADMINISTRATORS' PERCEPTIONS OF TEACHER EFFECTIVENESS

\section{LIST OF FIGURES}

Figure 1. Danielson's Framework for Teaching depicted with the four domains that are systemic or cyclical; Domain 1: Planning \& Preparation, Domain 2: Classroom Environment, Domain 3: Instruction, and Domain 4: Professional Responsibilities. No one Domain is more important than another. (Danielson Group, 2013).

Figure 2. Danielson's Framework for Teaching depicted with the four domains that are systemic or cyclical; Domain 1: Planning \& Preparation, Domain 2: Classroom Environment, Domain 3: Instruction, and Domain 4: Professional Responsibilities. No one Domain is more important than another.

Figure 3. Map of the MoMASSP eight regions in the state of Missouri.

Figure 4. Organizational Structure Chart of Northview School District

Figure 5. Danielson's Framework of Teaching expanded into Domain 1: Planning \& Preparation, Domain 2: Classroom Environment, Domain 3: Instruction, and Domain 4: Professional Responsibilities connected to the Missouri State Teaching Standards.

Table 1. Interview Participant's School Population

Table 2. Focus Group Participant's School Population 


\title{
ADMINISTRATORS’ PERCEPTIONS OF TEACHER EFFECTIVENESS
}

\begin{abstract}
The purpose of this qualitative case study was to help identify administrators' perceptions of effective teaching in rural Northwest Missouri in secondary public schools in order to increase teacher and administrator effectiveness. Current members of the Northwest chapter of the Missouri Association of Secondary School Principals participated in surveys, interviews, and a focus group to collect data to find common themes and trends. These methodologies indicated effective teaching is rooted in establishing relationships, high student/teacher engagement, student growth in content, high critical thinking, good classroom management skills, and the use of well-rounded classroom observation feedback.
\end{abstract}


ADMINISTRATORS' PERCEPTIONS OF TEACHER EFFECTIVENESS

\section{SECTION ONE:}

\section{INTRODUCTION TO THE DISSERTATION-IN-PRACTICE}

As the bell rings to start the day at Northview Middle/High School, students flood into the classrooms of their first hour courses to begin another day. Mr. Madison's history students enter the room and sit in their desks, organized in rows. Each day he has a worksheet placed on every desk waiting for the students to complete when the bell rings. On many occasions Mr. Madison delivers lectures aligned to the standards on his pacing guide and incorporates stories based on travels his family has experienced or documentaries he has viewed. Formative assessments, such as quizzes and worksheets and summative unit assessments are given on a regular basis and his test scores have proven to be higher than the state average. Students generally enjoy going to $\mathrm{Mr}$. Madison's class because they think he is interesting and can relate to him.

Mrs. Jefferson's English students enter the room, giving a high five to her as they walk past the door and go to get their writing prompt from the jar in the front of the classroom. Each day they have a different activity to complete when the bell rings. On many occasions Mrs. Jefferson divides the class period into whole group instruction and collaborative group time aligned to the standards on her pacing guide. Formative assessments, such as pair, share, and report, creating YouTube videos, or blogging and summative written or oral assessments and projects are given on a regular basis and her test scores have proven to be higher than the state average. Students generally enjoy going to Mrs. Jefferson's class because they think her class is fun. 


\section{ADMINISTRATORS' PERCEPTIONS OF TEACHER EFFECTIVENESS}

Based on the given information about both Mr. Madison and Mrs. Jefferson, what factors would identify each as an effective teacher? Does one display more effective teaching qualities than the other?

Education is constantly changing (Zhao, 2015). As society continues to advance and prepare students for the $21^{\text {st }}$ Century, the role educators play in providing effective classroom experiences are evolving. In the 1980's the role of the teacher was focused on instruction, decision making, creating a productive climate and attending to student motivation, planning lessons, addressing behaviors, and applying teaching methods in the classroom (Kindsvatter, Wilen, \& Ishler, 1988). In May of 2013, the Missouri Department of Elementary and Secondary Education developed the Missouri Educator Evaluation System that contains a document outlining the nine teacher standards (DESE, 2017).

These state standards of effective teaching focus on teachers constantly developing knowledge and skills while functioning as high-level practitioners: Standard 1- Content knowledge aligned with appropriate instruction; Standard 2- Student learning, growth and development; Standard 3- Curriculum implementation; Standard 4- Critical thinking; Standard 5- Positive classroom environment; Standard 6- Effective communication; Standard 7- Student assessment and data analysis; Standard 8Professionalism; and Standard 9- Professional collaboration (DESE, 2017). Within the nine teacher standards, there are a total of 36 quality indicators sporadically placed for the expectations of performance for effective teaching (See Appendix A). The elements that are associated with effective teaching methods, delivery, and craft are progressing as 


\section{ADMINISTRATORS' PERCEPTIONS OF TEACHER EFFECTIVENESS}

different student learners are emerging and it is the duty of the educator to serve each child's need.

Tirozzi (2001) noted, "Schools and classrooms that excite and challenge students and promote their creativity greatly support learning" (p. 436). Effective teaching has progressed and it is essential to obtain feedback from administrators to gain knowledge through research to explore the most vital qualities that produce effective teaching for students in rural Northwest Missouri. Arnold, Newman, Gaddy, and Dean (2005) pointed out that rural schools struggle to attract, recruit, and retain effective teachers (p. 4). Arnold et al. (2005) stated, "Three broad areas related to the quality of rural teachers need to be explored: (a) recruiting highly qualified teachers and inducting them effectively into rural schools; (b) providing effective teachers professional development that is aligned with research-based strategies and school improvement goals; and (c) retaining teachers in geographically isolated schools (p.18).

Khattri, Riley, and Kane (1997) echoed that the hardships and struggles rural schools face when honing in on effective teachers are evident, and when effective teachers are hired, acquiring the ability to retain and continue to professionally develop and grow teachers' skills is challenging. There is a need to determine administrators' perspectives of effective teaching in rural Northwest Missouri secondary public schools to help determine the role administrators play as instructional leaders to help attract, retain, coach, and shape effective teachers, as it is the duty of each school district to provide all students the best education possible, no matter the location of their school building. There are opportunities in rural school systems such as smaller class sizes, building relationships, familiarity with families, and local control, but there are 
ADMINISTRATORS' PERCEPTIONS OF TEACHER EFFECTIVENESS

challenges, such as decreasing enrollment and transient population, limited funding and resources, and a small teacher candidate pool, that educators must face and overcome to provide effective teaching and instruction.

\section{Statement of the Problem}

\section{Problem of Practice}

Creswell (2014) stated, "The problem comes from a void in literature, and conflict in research results in the literature, topics that have been neglected in the literature; need to lift up the voice of marginalized participants; and 'real-life' problems found in the workplace, the home, the community, and so forth" (p. 20). The problem with current practice in the Northwest Missouri rural secondary public school area is the lack of gathered, informed administrators' perspectives of effective teaching among administrative groups. As the role of the administrator has shifted and instructional leadership has moved to the forefront, other responsibilities have not gone away, especially in small rural school where many instances show a single administrator in a building taking on all roles (Arnold et. al., 2005; Smith \& Addison, 2013; Tirozzi, 2001). Administrators are expected to not only focus on school culture, community outreach, being a change agent, promoting and actively using situational awareness, while providing resources, planning professional development, and being directly involved in curriculum, instruction, and assessment practices, but they also must evaluate the effectiveness of teachers (Waters, Marzano, \& McNulty, 2003).

In the state of Missouri, administrators use evaluation tools that vary from district to district to assess and provide feedback to teachers based on the nine Missouri Teacher Standards (DESE, 2017a) most notably the Missouri Educator Evaluation System (MEES 


\section{ADMINISTRATORS’ PERCEPTIONS OF TEACHER EFFECTIVENESS}

or Missouri Model), the Network for Education Effectiveness (NEE), or the Marzano Teacher Evaluation Model. There is a need to gather information to relay the most vital qualities effective teachers utilize from rural Northwest Missouri administrators' perspectives in order to collect information to provide supportive leadership for student and teacher success in the classroom. This data will also allow administrators to serve as effective instructional leaders, provide opportunities for the coaching of teachers to become effective or sustain effectiveness, and to retain the best teachers in rural communities.

\section{Existing Gap}

While research from Hattie (2012); Marzano, Pickering, and Pollock (2001); Wong and Wong (1998); DuFour (2006); Dagget (2014); and Rutherford (2016) addressing effective teaching, there is an existing gap in the research when looking specifically at the structure of small, rural schools and administrators' perceptions of effective teachers in secondary education. Current research does not address what rural Northwest Missouri secondary public schools, or schools of a similar demographic, need in a teacher candidate or current practitioners in order for them to thrive and for students to be successful. Khattri et al. (1997) commented, “[...] little research has been done on how to improve the qualifications and preparedness of rural educators; and the studies of rural teachers that do exist often do not describe strictly rural phenomena” (p. 91).

Much literature is based on generalizations with overall teacher effectiveness, not specific to rural demographic needs. According to Arnold et al (2005), "Identifying such interventions is difficult, however, due to a lack of high-quality research conducted in rural settings" (p. 1). Furthermore, Sherwood (as cited in Arnold et al., 2005) concluded, 


\section{ADMINISTRATORS’ PERCEPTIONS OF TEACHER EFFECTIVENESS}

"Relatively few scholars are studying rural education issues, and almost no funding is available to conduct education research in specifically rural contexts" (p. 1).

\section{Purpose of the Study}

The purpose of this qualitative bounded case study is to help identify administrators' perceptions of effective teaching in rural Northwest Missouri secondary schools. Considering the demographics, needs, opportunities, and challenges of the rural setting may better help identify what administrators perceive as effective teaching specifically based on rural public school factors. Rural schools, as opposed to urban schools, have been understudied and in many cases have not produced students who go on to get advanced degrees. According to Nicosia (2017), "Inequitable school funding to rural districts and the greater political influence of non-rural education advocates because of their sheer size — contributes to furthering inequity." Almy and Tooley (2012) discussed how in recent years effective teaching has been a hot issue for policy makers across the country and recommend that schools follow in the footsteps of others they have found that have had success in the areas of teaching and learning by focusing on strong leadership, a campus-wide commitment to improving instruction by analyzing student data and reflecting on practice, creating a collaborative environment, and building and sustaining strong teaching and learning conditions for all.

Kumari and Padhi (2014) conducted a study comparing rural and urban teacher effectiveness and found no significant effect on teacher effectiveness based on location, but remarked, "effectiveness of teachers is not only measured by his mastery over subject but also by their efficiency, competency, effective control over teaching class, leadership qualities, inter-human relations, cooperative behaviour and academic excellence" (p.27). 


\section{ADMINISTRATORS' PERCEPTIONS OF TEACHER EFFECTIVENESS}

Gao and Liu (2013) focused specifically on personality traits of teachers in their research study, as they wrote, "personality traits of effective teachers have been an important area of investigation" (p.84).

Rutherford (2016) based his research called The 23 Artisan Themes after observing more than 40,000 classrooms across the United States and developing themes honed in on the most important skills for the development of teaching. These 23 themes are broken into three areas: technical work, scientific aspects, and artistic nature (Rutherford Learning Group, 2016). Hattie (2012) discussed that expert teachers are not rooted in a singular teaching style, but are adaptable and adjust to the students and their learning in order to increase student achievement and success. Wong and Wong (1998) focused on a well-managed and succinct classroom involving high expectations, classroom routines, management, and procedures that were clearly demonstrated and communicated. Dufour (2006) deemed collaboration to be the key to success, while Daggett (2014) promoted rigor, relevance, and relationships as a means to student achievement. Experts have their perspectives as to the most important qualities that reflect effective teaching. This study will take into consideration administrators' perceptions of effective teaching in relation to some of the rural demographics and trends unique to Northwest Missouri and other regions of similar demographic. The student population in rural schools across Missouri is declining and fluctuation in population is inconsistent based on an increased transient population (Carr \& Kefalas, 2009; Longworth, 2008). Lack of resources and funding have been challenging in rural communities and created a disparity in many classrooms compared to more urbanized communities (Christie, 2001; Giannini, 2009). These factors also contribute to a decline 


\section{ADMINISTRATORS’ PERCEPTIONS OF TEACHER EFFECTIVENESS}

in recruiting and retaining teachers. The purpose of this study is to research administrators' perspectives of effective teaching in rural Northwest Missouri secondary public schools when considering the rural school setting.

\section{Research Question}

Qualitative research questions are designed to address a void in the literature by analyzing emerging themes and connections to produce thick, rich descriptions (Creswell, 2014; Merriam \& Tisdell, 2016). The overarching research question guiding this study is: What are the administrators' perceptions of effective teaching in rural Northwest Missouri secondary public schools?

\section{Conceptual Framework}

Danielson (2010) stated, “It's not sufficient to say, 'I can’t define good teaching, but I know it when I see it"” (p.38). Danielson (2013) created the Framework for Teaching which is a research-based effectiveness model divided into four domains and 22 segments of effective teaching. This framework, grounded in a constructivist view of teaching and learning, is partitioned into four domains: planning and preparation, classroom environment, instruction, and professional responsibilities (Danielson Group, 2013). The four domains are the funnels of this framework through which all effective teaching passes. Observations were conducted, collected, and scored in over 3,000 classrooms to produce data focused on effective teaching for the Danielson Framework for Teaching. The following key findings were generated: "effective teaching can be measured, balanced weights indicated multiple aspects of effective teaching, and adding a second observer increases reliability significantly more than having the same observer score an additional lesson” (Bill and Melinda Gates Foundation, 2013, p.4-5). 


\section{ADMINISTRATORS’ PERCEPTIONS OF TEACHER EFFECTIVENESS}

Danielson (2013) explained that within the framework, shown in Figure 1, there is not one domain that is more important than the other, but instead they all work together to create the most conducive learning experience for students. At the same time, it has been noted that further research could be useful to see if there is more importance placed on one domain than another (Danielson Group, 2013). For example, observers reported that Domain 2, classroom environment, was typically more of a focus prior to Domain 3, instruction; this may be due to sequential need and prioritization rather than importance, but the model still shows how the four domains are cohesive and systemic in nature. Danielson (2010) explained effective teaching is not just what goes on in the classroom that you see when you walk into the room, but also consists of the "behind-the-scenes work of planning and other professional work, such as communicating with families and participating in a professional community" (p.36). It is important to have communication, evaluation, and feedback between teachers and administrators to ensure teacher quality consisting of a consistent definition of good teaching, a shared understanding of this definition, skilled evaluators, promoting professional development, and finding time for professional conversations (Danielson, 2010, p. 36-39). 


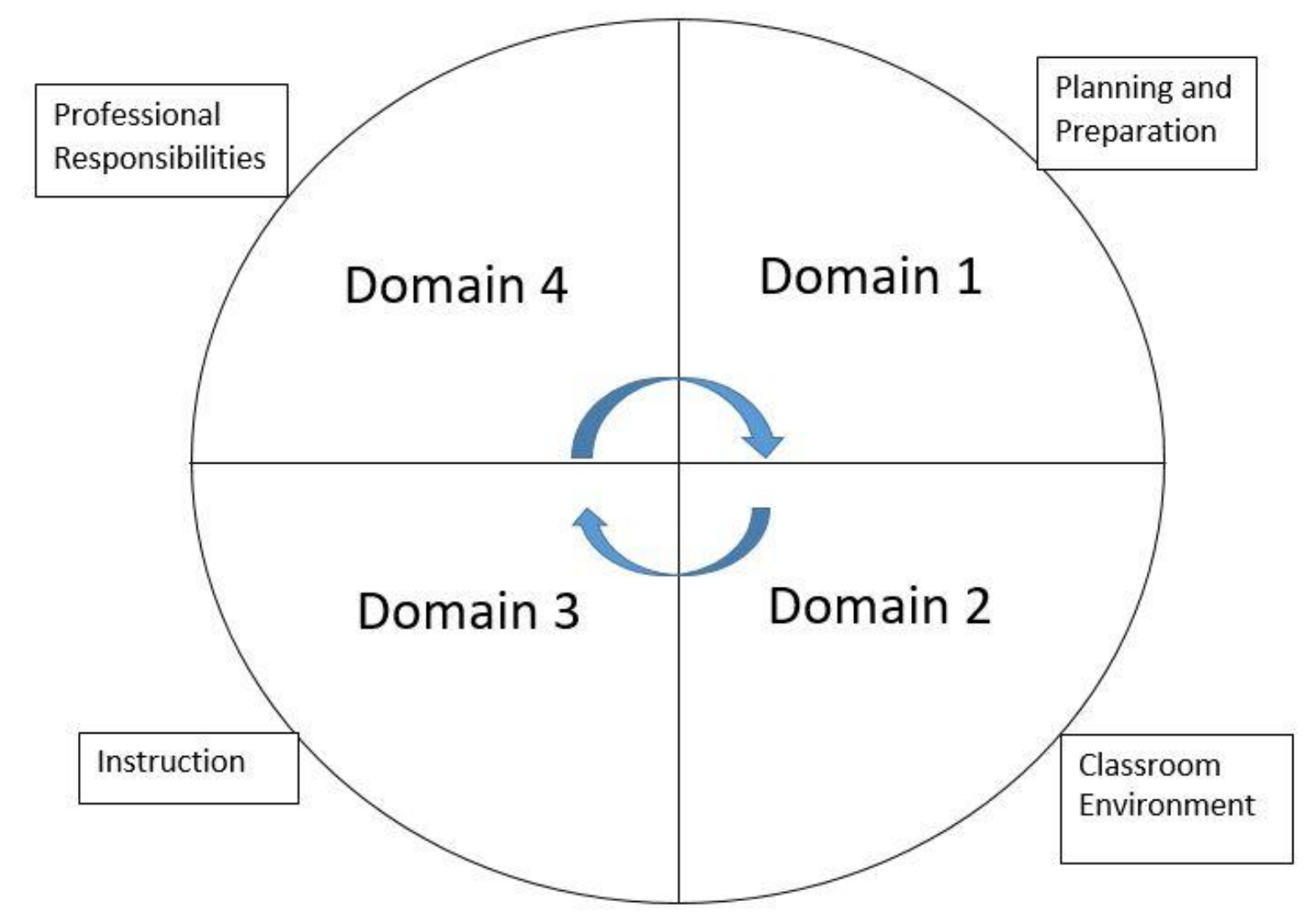

Figure 1. Danielson's Framework for Teaching depicted with the four domains that are systemic or cyclical; Domain 1: Planning \& Preparation, Domain 2: Classroom Environment, Domain 3: Instruction, and Domain 4: Professional Responsibilities. No one Domain is more important than another.

Danielson (2013) created the Framework for Teaching, a research-based effectiveness model divided into four domains and 22 segments of effective teaching. This framework, grounded in a constructivist view of teaching and learning, is partitioned into four domains: planning and preparation, classroom environment, instruction, and professional responsibilities (Danielson Group, 2013). The four domains are the funnels of this framework for which all effective teaching passes through.

\section{Domain 1: Planning and Preparation}

The first domain of the Framework for Teaching is focused on planning and preparation and is divided into six subsections of emphasis (Danielson Group, 2013). 


\section{ADMINISTRATORS’ PERCEPTIONS OF TEACHER EFFECTIVENESS}

Within this phase, educators show concern in content knowledge, pedagogy, demonstrating knowledge of the students, setting instructional outcomes, utilizing appropriate resources, designing coherent instruction in a variety of settings, and designing aligned assessments based on standards and student outcomes (Danielson Group, 2013).

\section{Domain 2: The Classroom Environment}

The second domain of the Framework for Teaching is focused on the classroom environment and is divided into five subsections of emphasis (Danielson Group, 2013). Within this phase, educators show concern in creating an environment of respect and rapport, establishing a culture for learning, managing classroom procedures, providing high expectations to help manage student behavior, and the physical organization of space to enhance productivity (Danielson Group, 2013).

\section{Domain 3: Instruction}

The third domain of the Framework for Teaching is focused on instruction and is divided into five subsections of emphasis (Danielson Group, 2013). Within this phase, educators show concern in communicating with students; using effective questioning, discussion, and participative techniques; engaging students in learning through structured activities; using assessment data in instruction; and demonstrating flexibility and responsiveness to student outcomes (Danielson Group, 2013).

\section{Domain 4: Professional Responsibilities}

The fourth domain of the Framework for Teaching is focused on professional responsibilities and is divided into six subsections of emphasis (Danielson Group, 2013). Within this phase, educators show concern in reflecting on teaching to grow in his or her 


\section{ADMINISTRATORS’ PERCEPTIONS OF TEACHER EFFECTIVENESS}

practice; maintaining accurate records; communicating with families; participating in a professional community; growing and developing professionally; and showing professionalism through integrity, advocacy, decision-making, and ethical conduct.

\section{The Framework}

Danielson (2013) explained that within the framework, shown in Figure 1, there is not one domain that is more important than the other, but instead they all work interconnected to create the most conducive learning experience for students. Danielson (2006) believed effective teaching is not just what goes on in the classroom that you see when you walk into the room, but also consists of the "behind-the-scenes work of planning and other professional work, such as communicating with families and participating in a professional community" (p.36). It is important to have communication, evaluation, and feedback between teachers and administrators to ensure teacher quality consisting of a consistent definition of good teaching, a shared understanding of this definition, skilled evaluators, promoting professional development, and finding time for professional conversations (Danielson, 2010, 36-39). The Danielson Framework is the framework through which this study is viewed. Three key variables were explored throughout this study: effective teaching, the administrators' role as an instructional leader, and the rural school setting as related to instructional opportunity. These are the pillars on which this research is grounded and it is viewed through the lens of Danielson's research. 


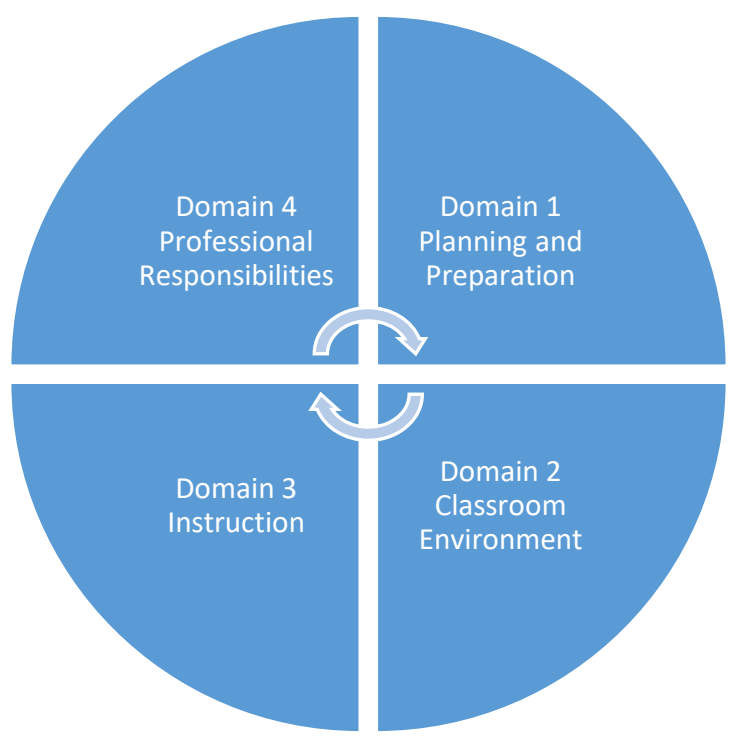

Figure 2. Danielson's Framework for Teaching depicted with the four domains that are systemic or cyclical; Domain 1: Planning \& Preparation, Domain 2: Classroom Environment, Domain 3: Instruction, and Domain 4: Professional Responsibilities. No one Domain is more important than another.

\section{Design of the Study}

As this research study was intended to measure administrators' perceptions of teacher effectiveness in rural Northwest Missouri, a qualitative case study was conducted (Creswell, 2014; Merriam \& Tisdell, 2016). Creswell (2014) described this approach as one for, "exploring and understanding the meaning individuals or groups ascribe to a social or human problem" (p.4). Merriam and Tisdell (2016) further explained, “Thus qualitative case studies share with other forms of qualitative research the search for meaning and understanding, the research as the primary instrument of data collection and analysis, an inductive investigative strategy, and the end product being richly descriptive" (p.37). 


\section{ADMINISTRATORS’ PERCEPTIONS OF TEACHER EFFECTIVENESS}

\section{Setting}

The setting for this study was specifically located in the Northwest region of Missouri designated by the Regional Professional Development Center (RPDC). The Northwest Missouri Regional Professional Development Center (NW RPDC) region five serves 61 school districts in Northwest Missouri. The average school district in this region would range from 400-550 students enrolled in Kindergarten through Twelfth grades, have a free and reduced lunch rate of 55-65\%, and have a population of primarily Caucasian students. Members of the Northwest chapter of the Missouri Association of Secondary School Principals currently practice in school districts that reside within this region. The RPDC catchment area contains fifteen counties, many containing secondary schools with rural demographics. This setting was purposeful as it allows for the demographics of the schools to be of a similar nature and many displaying rural characteristics (Merriam and Tisdell, 2016).

\section{Participants}

Participants were purposefully selected to participate in this research study. "Purposeful sampling is based on the assumption that the investigator wants to discover, understand, and gain insight and therefore must select a sample from which the most can be learned" (Merriam \& Tisdell, 2016, p.96). Current members of the Missouri Association of Secondary School Principals (MoASSP), Northwest chapter, in the Northwest RPDC region were selected to participate in a purposeful convenience sample. There are currently 88 members in the Northwest chapter of MoASSP ranging from assistant principals to recently retired principals; all were initially contacted to participate in this study. This sample was conducted as a purposeful convenience sample "based on 
ADMINISTRATORS' PERCEPTIONS OF TEACHER EFFECTIVENESS

time, money, location, availability of sites or respondents" (Merriam \& Tisdell, 2016, p.98).

\section{Data Collection Tools}

Three data collection tools were used to establish triangulation as defined by Merriam and Tisdell (2016) and Creswell (2014) to create validation and saturation. The data collection tools selected for this study began with surveys, designed with guidance from Fink (2017) composed of open ended questions, distributed online through email to current members of the MoASSP Northwest chapter. The survey utilized feedback responses on open-ended designed questions (Fink, 2017). Survey questions were constructed through the lens of the Danielson Framework (2013).

Interviews were designed and conducted with practices employed from Seidman (2013) and Merriam and Tisdell (2016) with questions based on the Danielson Framework (2013) until categories became apparent, themes emerged, and saturation occurred. The researcher used "highly structured interviews" conducted in person, via phone, or via teleconferencing (Merriam \& Tisdell, 2016, p.109).

Finally a focus group, consisting of secondary principals and administrators from the MoASSP, was composed and structured with questions based on the Danielson Framework (2013) and methods supported by Krueger and Casey (2015), "the focus group is characterized by homogeneity but with sufficient variation among participants to allow for contrasting opinions...the guiding principle is the degree to which these factors [occupation, past use of program or service, age, gender, and/or family characteristics] will influence sharing within the group discussion" (p.81). Lincoln and Guba (1985), as 


\section{ADMINISTRATORS’ PERCEPTIONS OF TEACHER EFFECTIVENESS}

referenced in Merriam and Tisdell (2016), "recommend sampling until a point of saturation or redundancy is reached" (p.101).

\section{Data Analysis}

During the data analysis process, the researcher recorded and transcribed all responses and utilized member check of transcriptions, scrutinized responses for emerging themes from interviews and the focus group conducted through first using open coding, followed by axial coding (Creswell, 2014; Merriam \& Tisdell, 2016; Seidman, 2013). Once the data was analyzed, major categories were created, and sub-category descriptors devised. "Researchers make interpretations of the statistical results, or they interpret the themes or patterns that emerge from the data" (Creswell, 2014, p.17). The researcher then created a table to display the findings and had the table cross-referenced to check for validity from participants (Merriam \& Tisdell, 2016; Seidman, 2013).

\section{Limitations, Delimitations, and Assumptions}

\section{Limitations}

Limitations are shortcomings, surroundings, or biases that the researcher cannot control, but that need to be mentioned in order to receive a holistic view of the study which has been conducted (Creswell, 2014). The researcher has been a member of MoASSP and an administrator in the Northwest region and has also been a secondary teacher. The roles the researcher has assumed may influence some ideation, but the researcher has been trained to refrain from allowing bias to enter into any research conducted, analyzed, or presented in this study. 


\section{ADMINISTRATORS’ PERCEPTIONS OF TEACHER EFFECTIVENESS}

\section{Delimitations}

This was a bounded case study and was conducted with the Northwest region of the RPDC in the state of Missouri (Creswell, 2014). This may limit the findings of the research given the rural area, location, and only including members of MoASSP in the region. There are no urban areas represented in this sample. Elementary level principals and administrators were not consulted in the process and may have brought differing opinions and views that may have impacted the data collected that were not represented.

\section{Assumptions}

The researcher is not familiar with all participants of the study and there are assumptions that are present. The researcher assumed participants in the case study have provided honest information and answered all interview and survey questions truthfully. It is the researcher's assumption the participants cooperated to provide quality information to improve scholarship and practice, not for any personal reason. The researcher made the assumption the participants had prior knowledge of and responsibilities for evaluating teacher effectiveness and providing feedback to teachers in their buildings.

\section{Definition of Key Terms}

Administrator. For the purpose of this paper an administrator is defined as a person who provides or has provided oversight to a secondary education program or building.

CSIP. Comprehensive School Improvement Plan

DESE. Department of Elementary and Secondary Education 
ADMINISTRATORS’ PERCEPTIONS OF TEACHER EFFECTIVENESS

Effective Teaching. Danielson's Framework for Teaching will be used a holistic systemic roadmap and provide the lens to view effective teaching by establishing the four domains of planning and preparation, classroom environment, instruction, and professional responsibilities.

Feedback. Wiggins (2012) defines feedback as information about how we are doing in our efforts to reach a goal.

MAESP. Missouri Association of Elementary School Principals

MASA. Missouri Association of Superintendents Association

MEES. Missouri Educator Evaluation System

Missouri Department of Elementary and Secondary Education (DESE).

Missouri Department of Elementary and Secondary Education is a result the of Missouri Constitution in 1945 (DESE, 2017).

Missouri Education Evaluation System (MEES). Missouri Education

Evaluation System is an evaluation system that contains documents outlining the nine teacher standards (DESE, 2017).

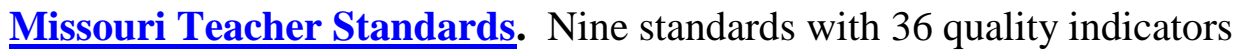
developed by DESE to guide teachers. These standards convey the expectations of performance for professional teachers in Missouri (DESE, 2017a).

MoASSP. Missouri Association of Secondary School Principals

MO PTA. Missouri Parent Teacher Association

MNEA. Missouri National Educators Association

MSBA. Missouri School Board Association

MSIP. Missouri School Improvement Program 
ADMINISTRATORS' PERCEPTIONS OF TEACHER EFFECTIVENESS

MSTA. Missouri State Teacher Association

NASSP. National Association of Secondary School Principals

NEE. Network of Educator Effectiveness

NWMoASSP. Northwest Missouri Association of Secondary School Principals

Perception. Merriam-Webster (2017) defines perception as "a way of regarding, understanding, or interpreting something; a mental impression."

Professional Learning Communities (PLC). An ongoing process in which educators work collaboratively in recurring cycles of collective inquiry and action research to achieve better results for the students they serve. Professional learning communities operate under the assumption that the key to improved learning for students is continuous job-embedded learning for educators (Dufour, 2006).

RPDC. Regional Professional Development Center

Rural. According to Khattri, Riley, and Kane (1997) "if an area has a population of less than 2,500 people, it is defined as rural" (p.80).

Secondary Public School. For the purpose of this paper a secondary public school will be defined as a non-private school at the middle or high school level, typically for grades anywhere from sixth through twelfth.

STEAM. Science Technology Engineering Arts Math

Teacher. Merriam-Webster (2017) defined the role of a teacher as "a person or thing that teaches something; especially: a person whose job is to teach students about certain subjects". The state of Missouri defined a teacher as someone who holds a baccalaureate degree or higher from a college or university (DESE, 2017). 
ADMINISTRATORS’ PERCEPTIONS OF TEACHER EFFECTIVENESS

\section{Significance of the Study}

\section{Scholarship}

There is a gap in research on administrators' perceptions of effective teaching practices and specifically effective teaching in rural areas. This qualitative bounded case study added to that literature and helped provide the perceptions of administrators in the Northwest region of MoASSP who use a variety of different evaluation tools to observe teacher effectiveness. Teacher effectiveness and performance have a direct impact on student performance (Almy \& Tooley, 2012). Data collected from this study presented common and differing factors in qualities of teacher effectiveness.

\section{Practice}

Research collected from this study provided relevant information for the field of education. The significance of this study was to inform principals and other administrative practitioners in rural Northwest Missouri current administrators' perceptions of effective teaching in secondary classrooms. This study will be beneficial to the instructional leaders of rural Northwest Missouri to help indicate ways to coach and provide instructional leadership to impact teacher effectiveness. This study will give further insight into attracting teacher candidates and retaining current teacher practitioners by understanding administrators' perspectives of effective teaching in secondary classrooms from this region's instructional leaders.

\section{Summary}

The world of education is constantly changing (Zhao, 2015). Due to transformations in our society and advancements needed to provide for all students, it is important to collect and reflect on administrators' perspectives of teacher effectiveness to 
help inform the instructional leadership practices and the hiring and retention challenges rural districts face. As educators it is important that quality and effectiveness are displayed at a high level and students are prepared for college or the workplace upon graduation. In order to do this, teacher effectiveness needs to be examined to provide equity in classrooms.

Teachers are at the frontline and have the most impact on student learning and achievement (Almy \& Tooley, 2012). Administrators must hire effective teachers, coach effective teachers, give quality feedback to ensure effective teaching, and retain effective teachers, but first there must be a consistent understanding of what qualifiers point toward effectiveness. This study captured the administrators' perceptions of teacher effectiveness in rural Northwest Missouri at the secondary level. 
ADMINISTRATORS' PERCEPTIONS OF TEACHER EFFECTIVENESS

\section{SECTION TWO: PRACTITIONER SETTING FOR THE STUDY}

Administrators use a variety of elements and protocols to evaluate teacher

effectiveness, including the Missouri Educator Evaluation System (MEES or Missouri

Model), the Network for Education Effectiveness (NEE), the Marzano Teacher

Evaluation Model, and several others decided at the local level. Many evaluation

systems are based on the same foundational Missouri Teacher Standards (DESE, 2017a),

but differ in the frameworks, feedback format, and structure through which the

evaluations are conducted. Teacher effectiveness is the key to student achievement and

administrators are essential to providing feedback on effectiveness to increase

performance and impact student learning and teacher performance (Haycock, 1998; Almy

\& Tooley, 2012).

\section{Background}

The Northwest Missouri Regional Professional Development Center (NW RPDC) region five serves 61 school districts in Northwest Missouri. The average school district in this region would range from 400-550 students enrolled in Kindergarten through Twelfth grades, have a free and reduced lunch rate of 55-65\%, and have a population of primarily Caucasian students. The mission of the NW RPDC is to "build the capacity of educators and schools to maximize student performance through high quality professional development" (RPDC, 2018). These facilitators provide professional development on site at school districts or collaborative learning workshops for several districts to help grow effective teaching and schools. Their vision states, "Professional development and support for schools is delivered through regional learning centers comprised of content specialists with expertise to meet school/district needs. These teams model a 
ADMINISTRATORS' PERCEPTIONS OF TEACHER EFFECTIVENESS

collaborative, seamless learning community and facilitate goal-alike networks to promote and sustain effective schools" (RPDC, 2018).

\section{History of the Organization}

The Missouri Association of Secondary State Principals (MoASSP) is a state affiliate of the National Association of Secondary School Principals (NASSP). The state coordinator is the official liaison with NASSP. MoASSP is in regular dialogue with the

\section{MASSP Map of 8 Regions}

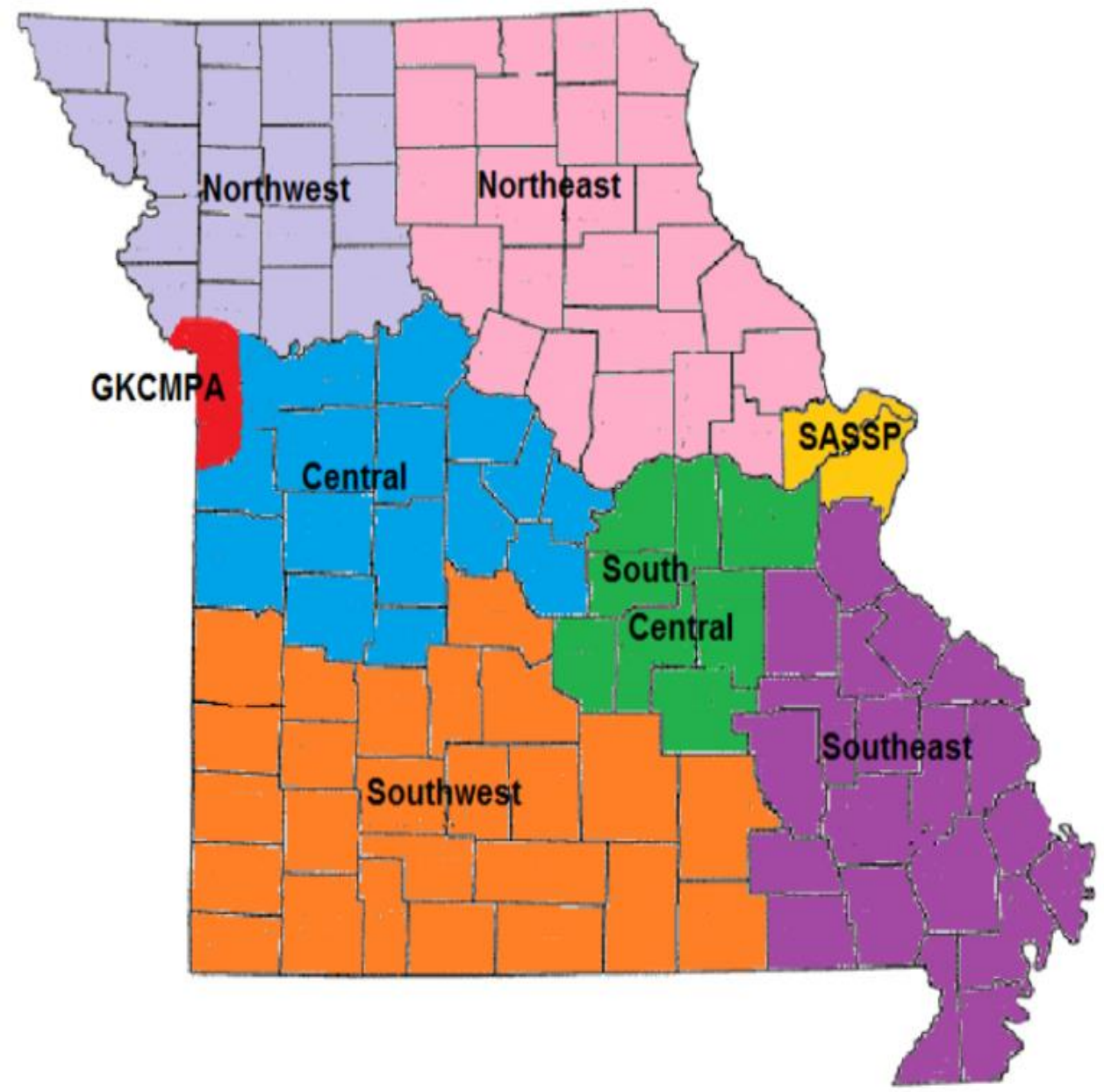

Figure 3. Map of the MoMASSP eight regions in the state of Missouri. 


\section{ADMINISTRATORS' PERCEPTIONS OF TEACHER EFFECTIVENESS}

Missouri Department of Elementary and Secondary Education (DESE). A liaison committee meets quarterly with the Commissioner of Education and DESE staff. The Association maintains contact with members of the Missouri General Assembly and the United States congress on legislative matters. The Board of Directors recommends legislative positions for the Association with input from members and district associations (MoASSP, 2018).

MoASSP maintains contact with other education organizations in the state. MoASSP works closely with the Missouri Association of Elementary School Principals, the Missouri Association of School Administrators, the Missouri State High School Activities Association and the Missouri School Boards Association. MoASSP is a part of the Missouri Education Round Table, which includes MAESP, MASA, MO PTA, MNEA, MSBA, and MSTA. Contacts are also maintained with colleges and universities (MoASSP, 2018). The association is divided into eight regions across the state with individual chapters. The mission of MoASSP is to improve secondary education through positive leadership and the enhancement of student performance. Within the strategic plan, the association should be involved in the following: providing information and leadership; encouraging research and service; promoting high educational standards; focusing attention, advocating and organizing as necessary for relevant state and federal education issues; providing for the general welfare of principals; working with other educational organizations; and following sound financial practices to support the mission of the association (MoASSP, 2018). This professional organization has supported administrators since 1925 and continues to serve current principals, assistant principals, aspiring principals, and retired principals at the secondary level. 


\section{ADMINISTRATORS' PERCEPTIONS OF TEACHER EFFECTIVENESS}

\section{Organizational Analysis}

The Northwest Region of MoASSP is comprised of 58 school district and 71 school administrators (C. Mershon, personal communication, August 29, 2018). These schools range in size from small rural schools, to larger suburban schools. All administrators have common ties by being in the same region, although some have different roles in their buildings they represent. One of the larger school districts represented in the Northwest region, Southview School District has a larger school structure, where the building administrators are more removed from the direct actions and decision-making of the super superintendent. Whereas, a smaller school structure representation from Northview School District shows the building principals playing a different role and assuming different responsibilities.

All schools report to DESE and are required to meet standards for accountability through the Missouri School Improvement Program (MSIP 5). Much of the data collected for accountability and school quality tie to teacher effectiveness: academic achievement, graduation rate, and college and career readiness (DESE, 2017). Although these school structures differ dramatically, their school leaders are members of the MoASSP and they are provided opportunities within the organization to work together, share different experiences, and network to improve practice (MoASSP, 2018). 


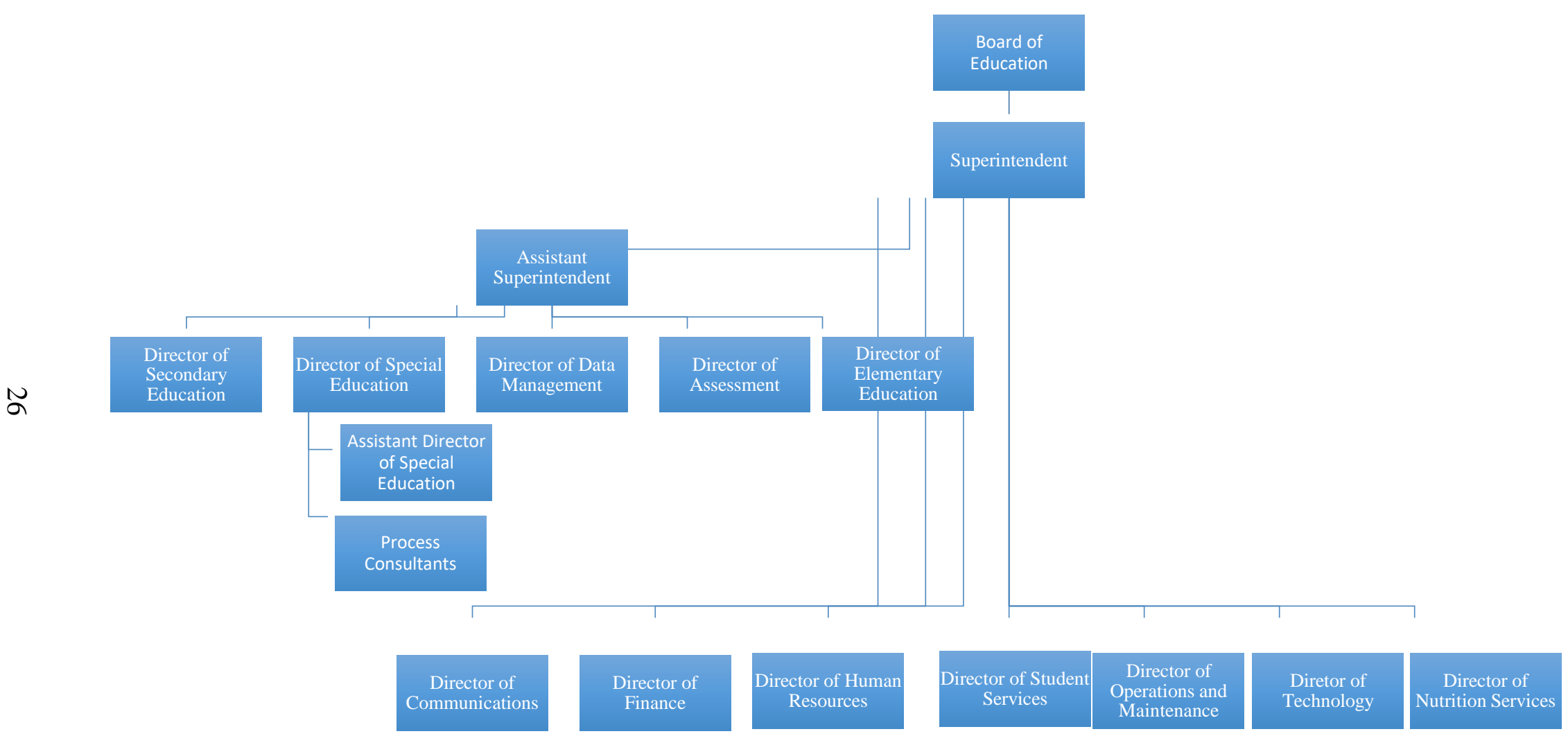

Figure 3. Organizational Structure Chart of Southview School District 


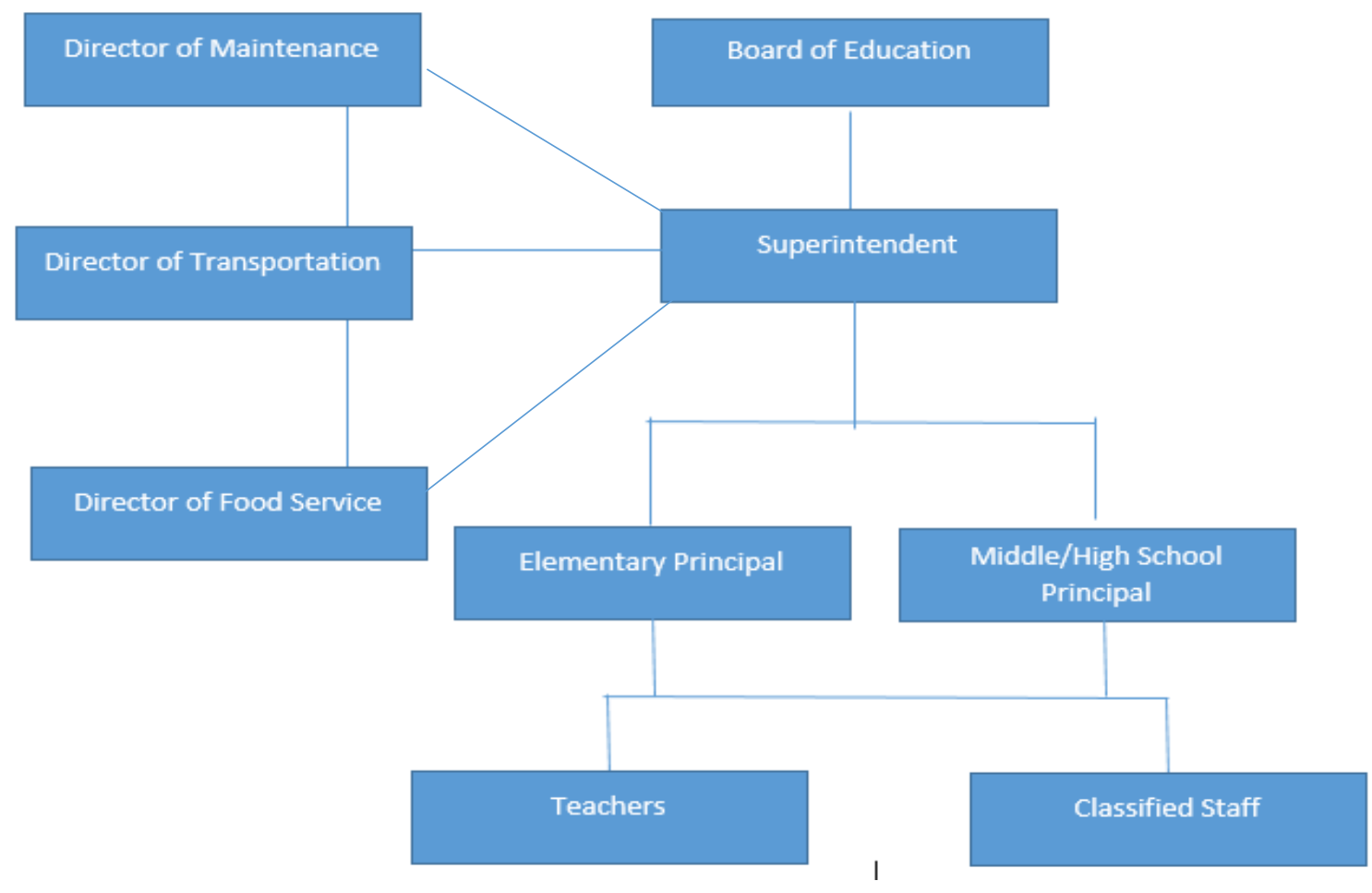

Figure 4. Organizational Structure Chart of Northview School District

\section{Leadership Analysis}

\section{Rural District Demographics}

When examining organizational leadership within NWMoASSP districts, there are varying structure types used determined by population, financial resources, and student need and demographic. The majority of districts within the NWMoASSP fall within a structure similar to Northview School District and are set in rural communities. Northview School District is located in Northwest Missouri and has a population of approximately 1,730 people. The school district is comprised of approximately 445 students in grades K-12. There are two buildings in this district: the middle/high school building, which services approximately 200 students in grades 6-12, and the elementary school, which services 215 students in grades K-5. The Elementary School also has an 


\section{ADMINISTRATORS’ PERCEPTIONS OF TEACHER EFFECTIVENESS}

early childhood program, which consists of two classrooms: one for the younger students servicing up to twenty, three and four year olds and two Pre-K, servicing up to thirty, four and five year olds. Each building has one principal and the district has a superintendent that is housed in the middle/high school building.

According to the Department of Elementary and Secondary Education (DESE) (2017), the number of students receiving free and reduced lunch in the Northview School District has increased over the past five years from $56.4 \%$ in 2013 to $65.2 \%$ in 2017 . The enrollment slightly decreased from 435 in 2013 to 409 in 2017, attendance rate slightly increased from $87.8 \%$ in 2013 to $89.6 \%$ in 2017 , and graduation rate improved from $97.44 \%$ in 2013 to $100 \%$ in 2017, showing positive aspects of growth in the student culture over the past five years. Approximately $96.8 \%$ of the student population is white, as ethnicity has remained constant over time.

As stated on the Northview School District website, the mission of the District is to develop independent and successful learners. It is the vision of the District that teachers engage in student-centered collaboration on the District level, working in each building, to create a unified team; students and staff collaborate to set goals to improve learning and increase school spirit by focusing on each child's talents; students take ownership of their future and become self-competitors; and students, staff, and the community ensure a safe environment for all students. The faculty value knowing and feeling responsible for all students, assisting students' transition through each stage of the school system, and being given opportunities for meaningful collaboration.

Northview School District, like many in the NWMoASSP region, is a Professional Learning Community (PLC). The District Leadership Team meets quarterly 


\section{ADMINISTRATORS' PERCEPTIONS OF TEACHER EFFECTIVENESS}

and the building leadership teams meet monthly to support the PLC process in each building and to plan professional development to support teachers. PLCs are focused on collaboration and continually working to improve instruction to enhance student success (Dufour, 2006). The district has been a 1:1 technology school district since the 20172018 school year and provides tablets to students in grades K-2 and chromebooks to students in grades 3-12 to utilize as a tool for educational performance. Each student is able to have a device provided by the school district to utilize throughout the school day as a learning tool to heighten the learning experience. Students in grades 3-12 are allowed to take the devices home with them in order to have access to online school work at home. The middle/high school building houses a Makerspace STEAM (science, technology, engineering, arts, and math) innovation room, which provides a collaborative space for creation and exploration and the elementary school is developing a similar ageappropriate room to open second semester of the 2018-2019 school year.

Northview School District's organizational leadership structure begins with the Board of Education, followed by the superintendent, then the building principals, followed by the directors, teachers, and the classified staff members. Each of these people play an important role in providing students a quality education. Since Northview is a smaller district, in the day-to-day operations Mintzberg (1979/2005) would best describe this organizational structure (and others similar to it) with the five-sector model description maintaining the strategic apex (superintendent) at the top, the middle line (building principal) in the middle with the directors and technostructure branching off, the operating core (teachers and classified staff) following on the front lines of command. As Selnick (1948) mentioned, all members of an organization bring qualities 


\section{ADMINISTRATORS’ PERCEPTIONS OF TEACHER EFFECTIVENESS}

that help mold the structure of the organization and help form and establish systems within the organization based on those who play a role.

\section{Board of Education}

The Board of Education is comprised of seven individuals who are voted into office and serve a three-year term. The board is organized with roles of president, vicepresident, treasurer, secretary, MSBA delegate, and board member. This unpaid elected position attends monthly meetings to reach three main goals: to make responsible decisions involving the school district's finances; review, approve, and adopt board policies; and hire and evaluate the superintendent.

\section{Superintendent}

The superintendent is hired by the board of education and serves as the Chief Executive Officer of the school district. The main goal of the superintendent is to meet and achieve the goals of the Comprehensive School Improvement Plan (CSIP). The CSIP focuses on five areas: student performance; highly qualified staff; facilities, support, and instructional resources; parent and community involvement; and governance (DESE, 2018). The superintendent is the final decision maker in day-to-day operations and is part of the Administrative Team, the Director's Group, and the District Leadership Team that participate in shared decision making.

\section{Principal}

Each building in the Northview school district has a principal that is in charge of day-to-day operations and reports directly to the superintendent. In the state of Missouri, a principal is expected to be a "competent manager and competent leader who continuously acquires new knowledge and skills and is constantly seeking to improve 


\section{ADMINISTRATORS’ PERCEPTIONS OF TEACHER EFFECTIVENESS}

their leadership practice to provide for high academic achievement for all students" (DESE, 2018). Principals are evaluated on six standards: vision, mission, and goals; teaching and learning; management of organizational systems; collaboration with families and stakeholders; ethics and integrity; and professional development. The principals at Northview are responsible for hiring teachers, instructional leadership, curriculum development, discipline, professional development, school culture, supervision, teacher evaluations, facility management, among other daily operations. The principals serve on the Administrative Team, the Director's Group, and the District Leadership Team and participate in shared decision making.

\section{Directors}

Directors oversee specific areas of operation and programs within a district. For example, the Northview School District has a Director of Food Service, Director of Maintenance, Director of Technology, and Director of Transportation. Directors report directly to the superintendent, but work closely with building principals. Directors are experts in their given field and have a focused area they pay close attention to and report out on a weekly basis at the Director's Group meeting about progress and concerns.

\section{Teachers}

DESE (2017a) stated, "effective teachers are caring, reflective practitioners and life-long learners who continuously acquire new knowledge and skills and are constantly seeking to improve their teaching practice to provide high academic achievement for all students." Teachers are evaluated on nine standards: content knowledge aligned with appropriate instruction; student learning, growth, and development; curriculum implementation; critical thinking; positive classroom environment; effective 
ADMINISTRATORS' PERCEPTIONS OF TEACHER EFFECTIVENESS

communication; student assessment and data analysis; professionalism; and professional collaboration. Teachers have direct contact with students on a daily impact. Haycock (1998) reported, "The difference between a good and a bad teacher can be a full level of achievement [for a student] in a single year" (p.61).

\section{Classified Staff}

Classified staff serve school districts in many capacities and play essential roles to the organization. From paraprofessional to secretary to custodian to cook, all adults in school buildings have an important piece to fulfill and make an impact on school culture and student learning.

\section{Implications for Research in the Practitioner Setting}

Teacher effectiveness directly impacts student learning outcomes (Coe et. al., 2014; Haycock,1998). Haycock (1998) reported three main impacts on effective teaching: strong verbal and math skills, deep content knowledge, and teaching skill. Over time, this has evolved and Coe et al (2014) more recently found six components of great teaching: content knowledge, quality of instruction, classroom climate, classroom management, teacher beliefs, and professional behavior. With the evolution of student learning, teaching, and the role of the administrator many times effective teaching is left to interpretation with the vague descriptions and numbers of frameworks available to use. The research conducted and data gleaned from this study will focus on Danielson's Framework (2014) and the current perceptions of administrators to explain common factors, qualities, discrepancies, and areas of improvement to assist instructional leaders to hire, retain, coach, and professionally develop effective teachers. There is a gap in 


\section{ADMINISTRATORS' PERCEPTIONS OF TEACHER EFFECTIVENESS}

research as to what practicing administrators' perceptions are specifically in low-income rural setting of effective teaching; this is needed to help build effective teachers.

\section{Summary}

The region selected for the practitioner setting is based on region five of the Northwest Regional Professional Development Center, serving 61 rural Northwest Missouri School Districts. Principals who are also in the Northwest Missouri Association of Secondary School Principals were selected to participate in this study. These administrators attend monthly meetings together and most participate in an annual conference. Administrators from school districts who participated in this study vary in size from 61 to 11,329 (DESE, 2017) and all have different backgrounds, but all have a common tie to rural education and membership to the NWMoASSP. 
ADMINISTRATORS' PERCEPTIONS OF TEACHER EFFECTIVENESS

SECTION THREE: SCHOLARLY REVIEW FOR THE STUDY

\section{Introduction}

Success of an educational program is largely dependent upon the quality of education provided from the teachers the school district employs to be instructing the students (Kumari \& Padhi, 2014; Thorpe, 2014). Every student deserves the same opportunity to learn and receive the best education from effective teachers and schools, no matter where they live. Rural school districts continuously search for effective teachers to educate students in order to produce successful citizens. "Rural schools face challenges in attracting and retaining teachers and administrators, limited financial resources, and issues with long-distance transportation. However, some of these difficulties are being addressed" (Teach: Make a Difference, 2017). After all, attracting and hiring educators, retaining effective teachers, or coaching teachers to become more effective are essential to provide all students with the best education possible by the school district. Thorpe (2014) stated, "The lack of consistency in the quality of teaching is most apparent in U.S. schools serving large numbers of poor children, where the job of teaching is more difficult and requires greater knowledge and skills for success than it does in schools serving more affluent children" (p. 2). In a study conducted at Fresno Unified School District in California Almy and Tooley (2012) reported that "teachers with similar performance could be judged as poor performers in one school but top performers in another, and feedback was inconsistent and not constructive" (p. 10). This study will look to see if the same phenomenon holds true in the Northwest region of Missouri and will add to the gap in research and literature to gain administrators' perceptions on effective teaching in these rural communities through the lens of 


\section{ADMINISTRATORS’ PERCEPTIONS OF TEACHER EFFECTIVENESS}

Danielson's Framework. The Danielson Framework model consists of four domains: Domain 1- Planning and Preparation, Domain 2- Classroom Environment, Domain 3Instruction, and Domain 4- Professional Responsibilities. These four domains work in unison to provide an effective teaching experience for both the teacher and the student and no one domain outweighs another (Danielson, 2017).

\section{Effective Teaching}

\section{Global View}

Best teaching practices and prescriptions for effective teaching have been discussed for decades (Baum \& Krulwich, 2016; Hattie, 2012; Marzano, Pickering, \& Pollock, 2001; Whitaker, 2012; Wong \& Wong, 1998). Wong and Wong (1998) set the ground work for most teachers with their best-selling publication The First Days of School, which relayed expectations of classroom management, to forming classroom procedures, to instructional strategies, and being an effective teacher. Wong and Wong (1998) promoted the idea of student success and teacher success holistically through specific strategies to implement as beginning teachers, or veteran teachers, on a daily basis, beginning on the first day of school.

Marzano, Pickering, and Pollock (2001) developed instructional strategies to assist teachers in becoming effective practitioners and to promote high student achievement. "Marzano's Nine" was developed, which encourages nine best practices of instructional strategies to be utilized by effective classroom teachers to produce success. Hattie (2003) indicated that "[teachers] account for about $30 \%$ of the variance. It is what teachers know, do, and care about which is very powerful in this learning equation" (p.

2). According to Hattie (2003), of the top ten influences on student success and 


\section{ADMINISTRATORS' PERCEPTIONS OF TEACHER EFFECTIVENESS}

achievement, teachers are a direct source of influence on eight of the factors. The eight influences that the effectiveness of the teacher directly impacts are "feedback, instructional quality, direct instruction, remediation/feedback, class environment, challenge of goals, peer tutoring, and mastery learning" (Hattie, 2003, p. 4). Hattie (2012) later developed five attitudes and beliefs of expert teachers:

- Expert teachers identify the most important ways to represent the subjects they teach

- Expert teachers create an optimal classroom climate for learning

- Expert teachers monitor learning and provide feedback

- Expert teachers believe all students can reach the success criteria

- Expert teachers influence a wide range of student outcomes not solely limited to test scores

Baum and Krulwich (2016) created the Artisan Teaching Model which indicated their definition of great teaching as such:

Great teachers are those who engage all students in compelling, rigorous activities that require higher-order thinking and allow them to articulate understandings verbally and in writing. They get students to think critically while inspiring confidence and building intellectual habits...Great teachers inspire on a daily basis, allowing students to have confidence in their own abilities, and measurable achievement results typically follow. (p. 1)

Whitaker (2012) discussed how great teachers do things differently and focused on seventeen things that mattered most for being effective in the field of education. Whitaker (2012) focused on setting high expectations for students and teachers, showing that teachers care, collaboration, being proactive, being reflective, putting students first, 


\section{ADMINISTRATORS’ PERCEPTIONS OF TEACHER EFFECTIVENESS}

having empathy, building relationships, and putting yourself in other's shoes to understand their situation.

Wygal and Stout (2015) conducted research among educators across the United States and found the top five qualities reported by teachers of effective classroom practices to be as followed listed in decreasing order of importance: "class session learning environment, student focus, preparation and organization, importance of the practice environment, passion and commitment to teaching (as a profession), and the design of the course learning environment" (p. 173). Gao and Liu (2013) concluded effective teachers, both across the United States and in China, demonstrated certain personality traits that assisted in his or her effectiveness. The twelve traits reported in the findings were "adaptability, enthusiasm, fairness, high expectations, good humor, patience, and responsibility, and that they are agreeable, caring, friendly, honest, and respectful” (p. 92).

After review of the literature and studies associated with effective teaching, Danielson's Framework for Teaching provides a holistic systemic roadmap which guides effective teaching by establishing the four domains of planning and preparation, classroom environment, instruction, and professional responsibilities. This framework offers a constructivist lens through which the global literature and studies may be viewed. 
ADMINISTRATORS' PERCEPTIONS OF TEACHER EFFECTIVENESS

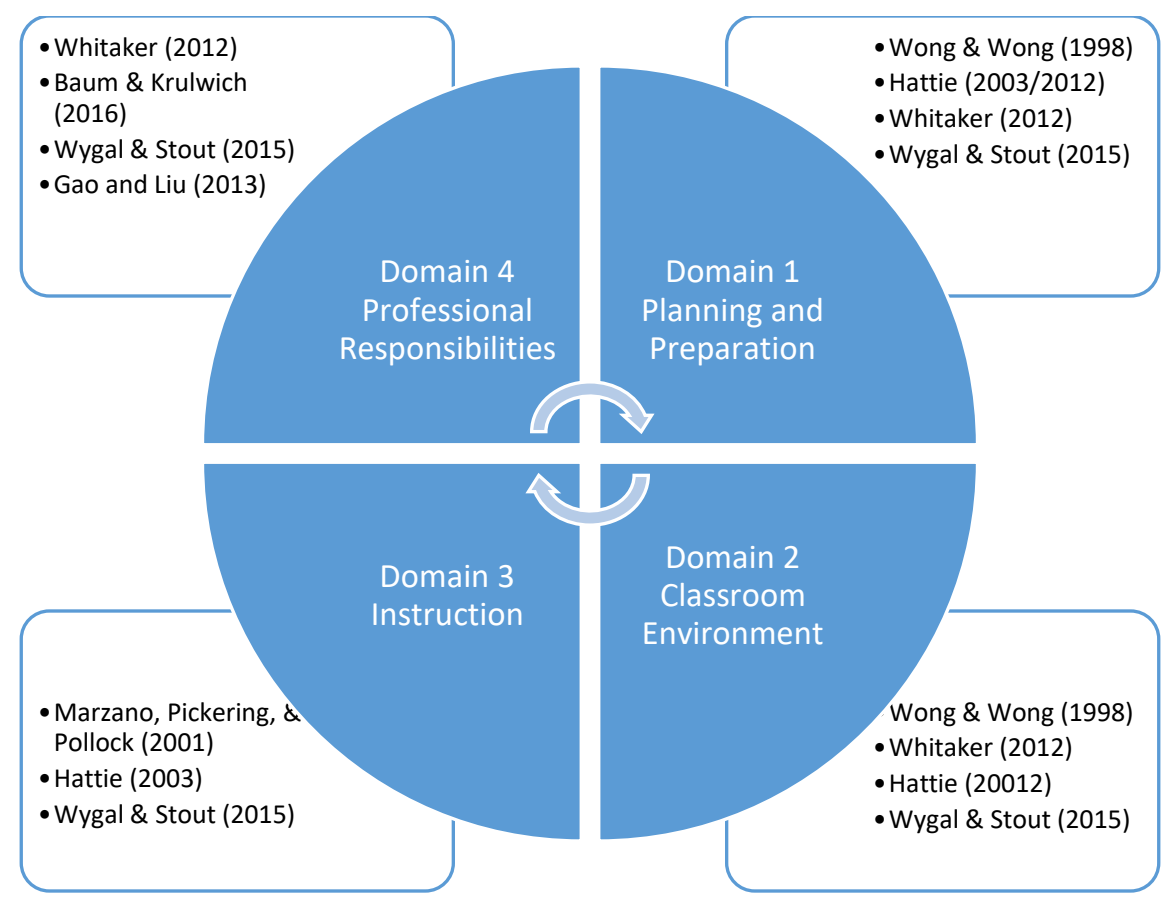

Figure 4. Danielson's Framework for Teaching expanded into Domain 1: Planning \& Preparation, Domain 2: Classroom Environment, Domain 3: Instruction, and Domain 4: Professional Responsibilities connected to recent literature and studies.

\section{Missouri State Teaching Standards}

In 2009, the state of Missouri adopted a new set of teaching standards to support effective teaching for educators across the state (DESE, 2017). These standards were revised in 2013 based on "teaching theory indicating that effective teachers are caring, reflective practitioners and life-long learners who continuously acquire new knowledge and skills and are constantly seeking to improve their teaching practice to provide high academic achievement for all students" (DESE, 2017). The Missouri Teacher Standards are a segment of the Missouri Educator Evaluation System and contain nine standards and 36 quality indicators (see Appendix A), all of which can be viewed through the lens of Danielson's Framework for Teaching (DESE, 2017a).

Content knowledge aligned with appropriate instruction. Standard one, content knowledge aligned with appropriate instruction, coincided with Domain 1: 


\section{ADMINISTRATORS’ PERCEPTIONS OF TEACHER EFFECTIVENESS}

Planning and Preparation. Within this standard are five quality indicators: content knowledge and academic language, student engagement in subject matter, disciplinary research and inquiry methodologies, interdisciplinary instruction, and diverse social and cultural perspectives (DESE, 2017a). Danielson (2006) pointed out that teachers must have a thorough basis of their content and an understanding of the resources, methods, and materials to utilize in order for students to be engaged in the subject matter being presented.

Student learning, growth, and development. Standard two, student learning, growth, and development, aligned among Domain 1: Planning and Preparation, Domain 2: Classroom Environment, and Domain 3: Instruction. Within this standard there are six quality indicators: cognitive, social, emotional, and physical development; student goals; theory of learning; differentiated lesson design; prior experiences, multiple intelligences, strengths, and needs; and language, culture, family and knowledge of community values (DESEa, 2017a). Danielson (2006) explained that the relationship between the development of a student and the construction of instruction goals needs to be reflective of one another and the particular needs of each student. Responding to students' needs on all levels, monitoring students, providing challenges and reinforcement, and building relationships through classroom interactions allows growth for both the student and educator to flourish (Danielson, 2006/2013).

Curriculum implementation. Standard three, curriculum implementation, aligned with both Domain 1: Planning and Preparation and Domain 3: Instruction. Within this standard there are three quality indicators: implementation of curriculum standards, lessons for diverse learners, and instructional goals and differentiated 


\section{ADMINISTRATORS' PERCEPTIONS OF TEACHER EFFECTIVENESS}

instructional strategies (DESE, 2017a). Danielson (2006) stressed effective teachers understand how content, instruction, and pedagogy complement one another and present the balanced combination in their craft, presentation, and daily classroom practices. Furthermore, Danielson (2013) concluded that when teachers have a solid grasp on content, curriculum, instruction, and pedagogy they are better prepared and more effective planners when it comes to differentiating instruction for diverse learners.

Critical thinking. Standard four, critical thinking, reflected Domain 1: Planning and Preparation, Domain 2: Classroom Environment, and Domain 3: Instruction. Within this standard there are three quality indicators: instructional strategies leading to student engagement in problem-solving and critical thinking; appropriate use of instructional resources to enhance student learning; and cooperative, small group, and independent learning (DESE, 2017a). Danielson (2013) reiterated high engagement and critical thinking for students beginning at a young age and extending life-long. Danielson's Framework (2013) promoted critical thinking in a variety of learning settings to extend content knowledge.

Positive classroom environment. Standard five, positive classroom environment, mirrored Domain 2: Classroom Environment. Within this standard there are three quality indicators: classroom management techniques; management of time, space, transitions, and activities; and classroom, school, and community culture (DESE, 2017a). Danielson (2013) focused on the classroom environment, not only as a physical space, but as a culture promoting respect and positive rapport where the teachers interact with the students and the students interact with one another. The classroom environment 


\section{ADMINISTRATORS’ PERCEPTIONS OF TEACHER EFFECTIVENESS}

must have procedures and transitions with expectations, responses, monitoring, and supervision (Danielson, 2013).

Effective communication. Standard six, effective communication, aligned with Domain 3: Classroom Environment and Domain 4: Professional Responsibilities. Within this standard there are four quality indicators: verbal and nonverbal communication; sensitivity to culture, gender, intellectual, and physical differences; learner expression in speaking, writing, and other media; and technology and media communication tools (DESE, 2017a). Danielson (2013) believed communication with students, parents, colleagues, and the community was impactful and of great importance to be effective. Communication with students is not only interacting with them in a personable way, but also setting expectations for learning, expectations for content, directions and procedures, use of oral and written language, providing feedback, monitoring learning, and responding to students in an appropriate manner.

Communication also extends to families to discuss the instructional program, about individual students, and engaging families in the school community (Danielson, 2013).

Student assessment and data analysis. Standard seven, student assessment and data analysis, coincided with Domain 1: Planning and Preparation and Domain 3: Instruction. Within this standard there are six quality indicators: effective use of assessments, assessment data to improve learning, student-led assessment strategies, effect of instruction on individual/class learning, communication of student progress and maintaining records, and collaborative data analysis (DESE, 2017a). Danielson (2013) reinforced that monitoring student progress through learning activities, criteria and 


\section{ADMINISTRATORS’ PERCEPTIONS OF TEACHER EFFECTIVENESS}

standards, and formative assessments to collect data that will guide and inform instruction promotes effective classroom teaching.

Professionalism. Standard eight, professionalism, corresponded to Domain 4: Professional Responsibilities. Within this standard there are three quality indicators: self-assessment and improving; professional learning; and professional rights, responsibilities, and ethical practices (DESE, 2017a). Danielson (2013) supported reflective teaching, growing and developing professionally, having integrity and ethical conduct, complying with school and district regulations, and having sound decisionmaking.

Professional collaboration. Standard nine, professional collaboration, paralleled Domain 4: Professional Responsibilities. Within this standard there are three quality indicators: induction and collegial activities, collaborating to meet student needs, and cooperative partnerships in support of student learning (DESE, 2017a). Participation in a professional community and formation of relationships with colleagues, participation in school projects, involvement in a culture of professional inquiry, and pride in service to the school and students are all pieces of effective teaching (Danielson, 2013). 
ADMINISTRATORS’'PERCEPTIONS OF TEACHER EFFECTIVENESS

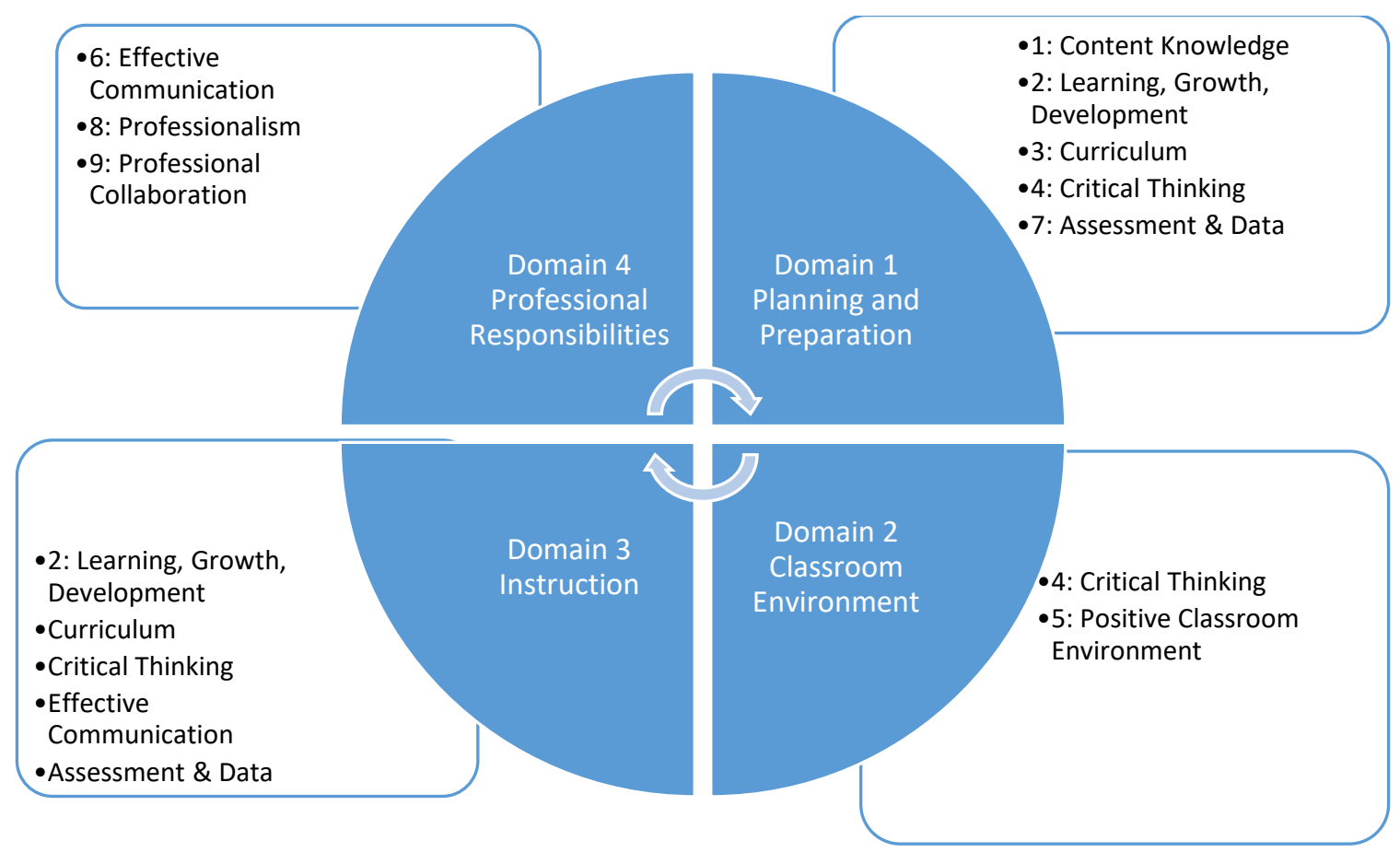

Figure 5. Danielson's Framework of Teaching expanded into Domain 1: Planning \& Preparation, Domain 2: Classroom Environment, Domain 3: Instruction, and Domain 4: Professional Responsibilities connected to the Missouri State Teaching Standards.

\section{Administrators' Role in Effective Teaching}

\section{Evolution}

When describing the role of the school principal in today's society, Tirozzi (2001) stated, "Without an understanding of the challenges ahead, a willingness to change, and an eye to encouraging each student to become a 'masterpiece,' schools fall far short in preparing today's students for tomorrow's complex and changing world" (p. 434).

Tirozzi also recounted, "At the dawn of this millennium the challenges for secondary schools and principals in the United States include changing demographics...principals trained to be managers rather than instructional leaders, and a dramatic shortage of qualified candidates willing to take on the principalship" (p. 435). Not only is the role of the school leader evolving, but the students all educators are serving are changing. "[...] 


\section{ADMINISTRATORS’ PERCEPTIONS OF TEACHER EFFECTIVENESS}

merely responding to the status quo will not be sufficient for tomorrow's schools"

(Tirozzi, 2001, p. 435). According to Tirozzo (2001), the role of the principal "must shift from a focus on management and administration to a focus on leadership and vision — on facilitating the teaching and learning process" (p. 438).

\section{Responsibilities as Instructional Leader}

Almy and Tooley (2013) recounted, “a principal's primary role is as a collaborator with teachers - supporting them as they work to improve their instruction and increase student achievement. In order to do this effectively, principals must maintain a pulse on teachers' instruction, making regular observations and conversations about practice imperative" (p. 11). Danielson (2013) suggested principals use supervision and evaluation as coaching opportunities to provide rich, meaningful feedback to teachers that will have an effect on instruction. According to Almy and Tooley (2012), leaders in Ascension Parish Public School in Louisiana promoted teacher professional development and accountability as an avenue to build and improve teacher effectiveness, satisfaction, and retention. Domain 4 in Danielson's Framework for Teaching (2013) focused on professional responsibilities. As stated by Smith and Addison (2013), instructional leadership encompasses a wide variety of elements: setting high, but achievable, academic goals; maintaining orderly learning environments; encouraging teachers' beliefs in their students' abilities to achieve; modeling respect for hard work and academic achievement; making supplies and instructional material as readily available; recognizing and rewarding teacher efforts; creating opportunities for progressive professional growth; finding time to share information; supporting teachers' use of new skills; creating incentives for 
ADMINISTRATORS' PERCEPTIONS OF TEACHER EFFECTIVENESS

student learning; honoring students for accomplishments and good citizenship; acknowledging teacher professionalism; and creating professional learning communities. (p. 136)

\section{Impact on Teacher Effectiveness}

Balkar (2015) conducted a study focusing on empowering teachers and creating a culture of trust to maximize effectiveness. The top five characteristics reported from Balkar (2015) of an Empowering School Culture directly related to the building administrator were a "sense of confidence, support for risk-taking, encouraging autonomy, freedom, and flexibility" (p. 213). Almy and Tooley (2012) reported a study in North Carolina where a principal was charged with improving instructional practices and promoting effective teaching among teachers. This leader changed conditions for teachers and provided support, collaboration, and positive working conditions to enhance student success. Teacher perception of their work environment was changed and there was a direct impact on student learning (Almy and Tooley, 2012).

Waters, Marzano, and McNulty (2003) discovered a direct relationship between school leadership and teacher effectiveness on student achievement. When school leaders focused their responsibilities on school culture, instructional resources, outreach with stakeholders, shared decision making, challenging the status quo, monitoring and evaluating the effectiveness of school practices, situational awareness, and ensured intellectual stimulation student achievement increased. Adversely, it was noted that at the same time, leaders who did not effectively employ these skills had a negative impact on teacher effectiveness, decreasing levels of student achievement (Waters, Marzano, \& McNulty, 2003). 


\section{ADMINISTRATORS' PERCEPTIONS OF TEACHER EFFECTIVENESS}

\section{Effectiveness in Rural School Setting}

\section{Rural School Demographics}

"The Census Bureau definition is based upon size and density of the population in an area. If an area has a population of less than 2,500 people, it is defined as rural" (Khattri, Riley, \& Kane, 1997, p. 80). “The salaries paid to rural teachers are significantly lower than the salaries paid to their nonrural counterparts" (Khattri, Riley, \& Kane, 1997, p. 91). A high population of rural schools are situated in "geographically isolated areas" (Arnold, Newman, Gaddy, \& Dean, 2005, p. 18).

\section{Teacher Effectiveness Impact in Rural School Setting}

Demographics of rural schools have an impact on teacher effectiveness (Arnold, et al, 2005; Barley \& Beesley, 2007; Kannapel \& DeYoung, 1999; Katthri, Riley, \& Kane, 1997; Shoulders \& Krei, 2015). Khattri, Riley, and Kane (1997) and Arnold et al (2005) explained that not only is teacher recruitment a struggle for rural area schools, but finding qualified staff members and providing adequate training for professional development is an ongoing problem. Khattri, Riley, and Kane (1997) cited negative impacts of rural school demographics on teacher effectiveness such as a smaller school budget, fewer course offerings, inconsistent course-taking patterns, limited availability of special programs, limited staff qualifications and preparedness, and fewer technology resources were echoed in several other studies. Concurrently, positive impacts such as higher parental involvement, stronger school-business relationships, having a sense of community, and smaller class sizes were also noted (Khattri, Riley, \& Kane, 1997).

Research according to Barley and Beesley (2007), presented success factors of rural schools related to teacher effectiveness. The top seven factors were, "high 


\section{ADMINISTRATORS’ PERCEPTIONS OF TEACHER EFFECTIVENESS}

expectations for all students; structural supports for learning; use of student data; alignment of curriculum, instruction, and assessment; individualization of instruction; teacher retention; and professional development" (p. 3-4). While some rural schools displayed success factors, others are focusing on three areas as school improvement is an ongoing struggle, “(a) recruiting highly qualified teachers and inducting them effectively into rural schools; (b) providing effective teacher professional development that is aligned with research-based strategies and school improvement goals; and (c) retaining teachers in geographically isolated schools" (p. 18).

\section{Summary}

While it is the fundamental goal for educators and school districts to provide the highest quality learning experiences for students, there is a challenge for many, especially in rural districts (Arnold et al, 2005; Barley \& Beesley, 2007; Khattri, Riley, \& Kane, 1997). There is a gap in literature that does not provide insight into administrators' perceptions of teacher effectiveness as the role of the administrator has evolved as the building instructional leader. Danielson (2013) has provided a Framework for Teaching which can be used to view effective teaching on a global scale and in the state of Missouri, the ever-changing role of the administrator, and the rural school setting. 
ADMINISTRATORS' PERCEPTIONS OF TEACHER EFFECTIVENESS

SECTION FOUR

CONTRIBUTION TO PRACTICE

Who: Attendees of the American Association of Colleges for Teacher Education (AACTE) National Conference

When: February 2020 72nd Annual AACTE National Conference in Atlanta, GA How: Through a presentation at the 2020 AACTE National Conference. The presentation will be given by the researcher along with a visual presentation.

\section{Type of Document}

Document type will be a visual presentation that will be presented at the 2020 Annual AACTE Conference. The visual presentation will inform the audience of administrators' perceptions of teacher effectiveness in rural Northwest Missouri secondary public schools. Upon request the full report can be made available.

\section{Rationale for this Contribution Type}

The 2020 Annual AACTE Conference is a collaboration of leaders across the country and provides a forum for educators to engage in meaningful discussions, share research and practices, and become better equipped to drive change in the educator preparation field. This conference provides networking and professional development opportunities for administrators to learn from one another from across the country. This presentation would be ideal for Strand I: Equity and Inclusivity in Preparation and Practice and address the question: In what manner are educator preparation programs adjusting their practices to address the needs of learners in urban, suburban, and/or rural districts? This research would be relevant to attendees of this conference.

\section{Outline of Proposed Contents}

Background on teacher effectiveness and the Danielson Framework 
ADMINISTRATORS' PERCEPTIONS OF TEACHER EFFECTIVENESS

The need for research on administrator perceptions of teacher effectiveness in rural secondary school settings

Design of the study

Findings (qualitative results according to Danielson Framework components)

Effective Teaching, Administrators Role in Effective Teaching, and Effectiveness in Rural School Setting through Danielson's Framework for Teaching

Recommendations for administrators as instructional leaders

Presentation

\section{Administrators' Perceptions of Teacher Effectiveness in Rural Northwest Missouri Secondary Public Schools}




\section{Research Study Presented By:}

- Sarah Barmann-Smith

- University of Missouri/Northwest Missouri State University

- ELPA EdD Program

- sabcn2@mail.missouri.edu

- sbarmannsmith@albany.k12.mo.us

\section{Statement of the Problem}

- Lack of gathered, informed administrators' perspectives of effective teaching among administrative groups

- The current role of the administrator has shifted- more of a focus on instructional leader

- Today's administrators are expected to focus on school culture, community outreach, being a change agent, promoting and actively using situational awareness, while providing resources, planning professional development, and being directly involved in curriculum, instruction, and assessment practices. In addition, they also must evaluate the effectiveness of teachers (Waters, Marzano, \& McNulty, 2003).

- Question of how to best serve a rural setting- students and teachers

To relay the most vital qualities effective teachers utilize from rural Northwest Missouri administrators' perspectives in order to collect information to provide supportive leadership for student and teacher success in the classroom. This data will also allow administrators to serve as effective instructional leaders, provide opportunities for the coaching of teachers to become effective or sustain effectiveness, and to retain the best teachers in rural communities. 


\title{
Purpose of this Research Study
}

\author{
- Help identify administrators' perceptions of effective teaching in rural \\ Northwest Missouri secondary schools and share with current \\ practitioners \\ - Positively impact teacher effectiveness through the administrative \\ role of instructional leadership
}

Considering the demographics, needs, opportunities, and challenges of the rural setting may better help identify what administrators perceive as effective teaching specifically based on rural public school factors. Furthermore, Sherwood (as cited in Arnold et al., 2005 ) concluded, "Relatively few scholars are studying rural education issues, and almost no funding is available to conduct education research in specifically rural contexts" ( $p$. $1)$.

\section{Research Question}

- The overarching research question guiding this study is:

What are the administrators' perceptions of effective teaching in rural Northwest Missouri secondary public schools?

Qualitative research questions are designed to address a void in the literature by analyzing emerging themes and connections to produce thick, rich descriptions (Creswell, 2014; Merriam \& Tisdell, 2016). Khattri et al. (1997) commented, “[...] little research has been done on how to improve the qualifications and preparedness of rural educators; and the studies of rural teachers that do exist often do not describe strictly rural phenomena" (p. 91). 


\section{Conceptual Framework}

\section{Danielson's Framework for Teaching}

Four Domains

- Planning and Preparation

- Classroom Environment

- Instruction

- Professional Responsibilities

(Danielson Group, 2013)

Grounded in a constructivist view of teaching and learning (Danielson Group, 2013).

\section{Danielson's Framework for Teaching}

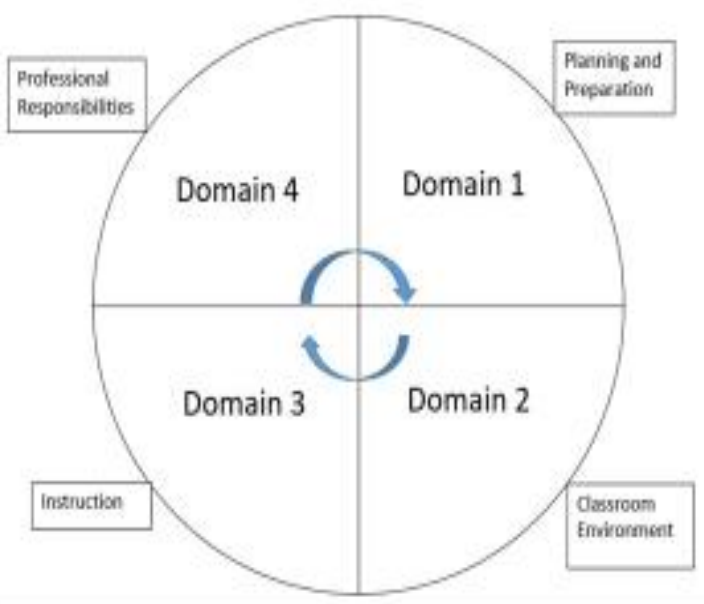

All four domains work together- no one is more important than another. 


\section{Design of the Study}

- Setting- the Northwest region of Missouri designated by the Regional Professional Development Center (RPDC).

- Participants- Current members of the Missouri Association of Secondary School Principals (MoASSP), Northwest chapter.

The Northwest Missouri Regional Professional Development Center (NW RPDC) region five serves 61 school districts in Northwest Missouri. The average school district in this region would range from 400-550 students enrolled in Kindergarten through Twelfth grades, have a free and reduced lunch rate of $55-65 \%$, and have a population of primarily Caucasian students.

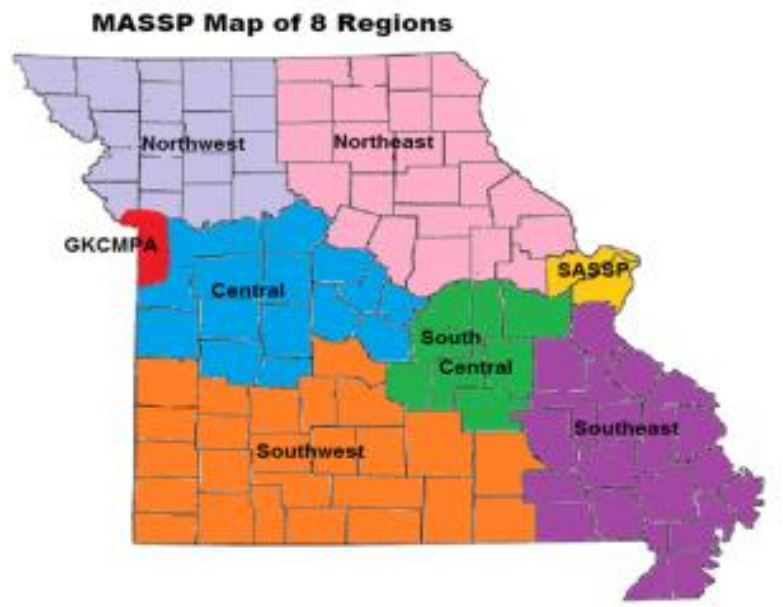

Missouri Association of Secondary School
Principals Map- Northwest region indicated. 


\section{Design of the Study}

- Data Collection Tools

- Surveys- open ended questions

- Interviews

- Focus Group

- Data Analysis

- Emerging Themes and Trends

- Open and Axial Coding Methods

- Validity and Assurance

(Creswell, 2014; Merriam \& Tisdell, 2016; Seidman, 2013).

Three data collection tools were used to establish triangulation as defined by Merriam and Tisdell (2016) and Creswell (2014) to create validation and saturation.

\section{Participants of Interviews}

\begin{tabular}{|l|l|}
\hline Interview Participant & $\begin{array}{l}\text { School Population of Building } \\
\text { Administrator }\end{array}$ \\
\hline Administrator A & 426 \\
\hline Administrator B & 249 \\
\hline Administrator C & 213 \\
\hline Administrator D & 324 \\
\hline Administrator E & 157 \\
\hline
\end{tabular}




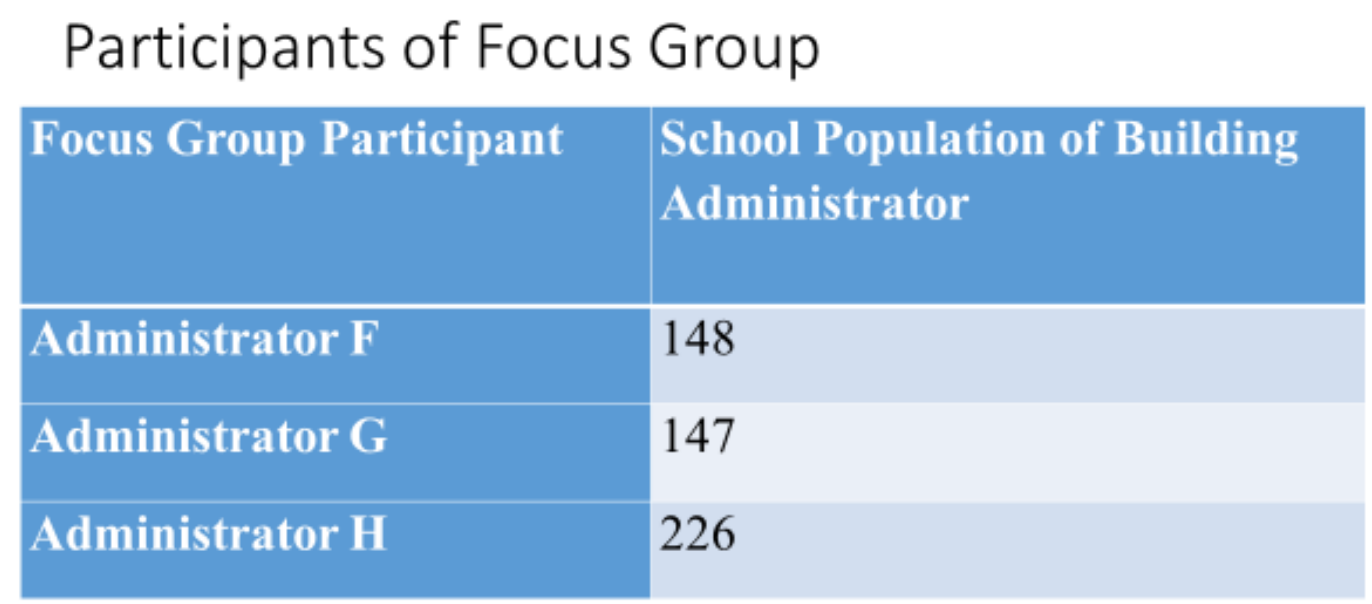

\section{Limitations and Delimitations}

- Limitations- The researcher has been a member of MoASSP and an administrator in the Northwest region and has also been a secondary teacher.

- Delimitations- Findings are limited to the rural Northwest Missouri area as this was a bounded case study. This study only consulted secondary level administrators- elementary principals were not selected as participants.

Limitations are shortcomings, surroundings, or biases that the researcher cannot control (Creswell, 2014). 


\section{Assumptions}

- Participants in the case study have provided honest information and answered all interview and survey questions truthfully.

- Participants cooperated to provide quality information to improve scholarship and practice, not for any personal reason.

- Participants had prior knowledge of and responsibilities for evaluating teacher effectiveness and providing feedback to teachers in their buildings.

\section{Findings}

- Domain 1: Planning and Preparation

- High student/teacher engagement

- Student learning/growth/progress in content

- Student performance on state assessments

- High critical thinking and depth of knowledge used in lessons

Within this phase, educators show concern in content knowledge, pedagogy, demonstrating knowledge of the students, setting instructional outcomes, utilizing appropriate resources, designing coherent instruction in a variety of settings, and designing aligned assessments based on standards and student outcomes (Danielson Group, 2013). 


\section{Domain 1: Planning and Preparation}

- High Student/Teacher Engagement

- Administrator A stated, "When you see positive relationships with students; when you walk in the room and students are engaged; when test scores are satisfactory and improving; when you witness collaboration among peers-you know a teacher is effective. You see students do more critical thinking and project-based learning."

\section{Domain 1: Planning and Preparation}

\section{- Student Growth and Performance}

- Administrator E pointed out, "Our teachers collaborate during their planning process and even extend that to neighboring schools to build a network. This makes it a 'working smarter not harder approach' for many of them."

- Administrator D said, "It is important for our teachers to be up-to-date on their curriculum, standards, and current practices. They need to have their lesson plans prepared and be flexible to serve our students, but also follow their pacing guides while they are planning so they are ready each day." 


\section{Domain 1: Planning and Preparation}

- High Critical Thinking/Depth of Knowledge

- Administrator H commented, "After each lesson, our most effective teachers realize a lesson they just presented was a huge success or conversely, a huge failure. They then build and adjust and look for the results in their students. If students are consistently engaged in a positive way and I see them differentiating for every student I know they are making gains."

\section{Findings}

\section{- Domain 2: Classroom Environment}

- Creation of a positive classroom environment

- Building positive relationships with students, colleagues, and community

- Having key characteristics: passion, motivation, dedication, commitment, and investment.

Within this phase, educators show concern in creating an environment of respect and rapport, establishing a culture for learning, managing classroom procedures, providing high expectations to help manage student behavior, and the physical organization of space to enhance productivity (Danielson Group, 2013). 


\section{Domain 2: Classroom Environment}

\section{- Creation of a positive classroom environment}

- Administrator A commented, "Our teachers have a way of making our students feel like shining stars. They interact with them on a personal level, getting to know them outside of school- their interests and families and most of them spend time with them outside of school as coaches or sponsors."

- Administrator F put it well, "Appreciating the unique rural-life values: family, community, agriculture, independence, and quality of life."

\section{Domain 2: Classroom Environment}

\section{- Building positive relationships}

- Administrator D said, "As a building we focus on building relationships with every student. We form a list of students who may be 'at-risk' and our teachers make a commitment to intentionally build relationships with them so each student has a sense of belonging. If a student is not plugged in at school, learning will not take place."

- Administrator H stated, "Teachers need to extend beyond the classroom and be immersed in the community. Many of our teachers attend activities and live in our community and this speaks volumes for them with our stakeholders." 


\section{Domain 2: Classroom Environment}

- Having key characteristics: passion, motivation, dedication, commitment, and investment.

- Administrator B commented, "You can tell almost immediately based on student engagement, classroom management, and the passion teachers are showing in their craft" while Administrator C added, "Effective teachers have it all- plus the extra gumption to get creative and innovative, to keep their classrooms fresh and motivate students to go the extra mile because they are."

\section{Domain 2: Classroom Environment}

- Having key characteristics: passion, motivation, dedication, commitment, and investment.

- Administrator B commented, "You can tell almost immediately based on student engagement, classroom management, and the passion teachers are showing in their craft" while Administrator $\mathrm{C}$ added, "Effective teachers have it all- plus the extra gumption to get creative and innovative, to keep their classrooms fresh and motivate students to go the extra mile because they are."

Within this phase, educators show concern in communicating with students; using effective questioning, discussion, and participative techniques; engaging students in learning through structured activities; using assessment data in instruction; and demonstrating flexibility and responsiveness to student outcomes (Danielson Group, 2013). 


\section{Domain 3: Instruction}

- High student/teacher engagement

- Administrator G reported, "Cognitive engagement of students, level of problem solving/critical thinking, motivation of students in the classroom, teachers ability to check for understanding during the lesson for the whole group and individuals enhancing the classroom experience for students."

\section{Domain 3: Instruction}

\section{- Student learning and growth}

- Administrator A responded, "I always talk to students about the instruction they receive- they will tell you. In an effective classroom, the students drive the conversation. The students demonstrate learning through their work, questions, participation, and passion." 


\section{ADMINISTRATORS' PERCEPTIONS OF TEACHER EFFECTIVENESS}

\section{Domain 3: Instruction}

- Critical thinking/depth of knowledge

- Administrator $\mathrm{H}$ rephrased and added, "Student engagement, building upon students' learning strengths and needs, problem solving and critical thinking, positive motivation and relation building. I look for engagement and signs of curiosity and grit. I want to see students involved and taking risks and I want to see a teacher facilitating those interactions."

\section{Domain 3: Instruction}

\section{- Individualized instruction}

- Administrator B stated, "My effective teachers are like a well-oiled machine. It's obvious the students know the expectations of the classroom, the content is being delivered in an engaging method, and all are focused on the daily lesson plan." 


\section{Domain 3: Instruction}

- Instructional Leaders Contribution

- Frequent classroom observations with feedback

- "Look fors" or focus indicators

- High student/teacher engagement

- Critical thinking

- Positive relationships

- Classroom management

- Quality assessments

Participants reported that most performed classroom walk-throughs or observations either daily or monthly, while others said they struggle to find time to get into classrooms and are unable to perform those duties as often as they would like.

\section{Findings}

- Domain 4: Professional Responsibilities

- Teacher characteristics

- Opportunities and challenges

- Professional development

- Teacher certification

Within this phase, educators show concern in reflecting on teaching to grow in his or her practice; maintaining accurate records; communicating with families; participating in a professional community; growing and developing professionally; and showing professionalism through integrity, advocacy, decision-making, and ethical conduct (Danielson Group, 2013). 


\section{Domain 4: Professional Responsibilities}

- Teacher Characteristics

- Passion for teaching, dedication, flexibility, and the ability to take on multiple responsibilities and teach several different classes.

- Administrator E said, "Rural schools need a person who can not only lead a classroom, but someone who can contribute in other ways and be more than just a teacher- they need to also be a coach, a class sponsor, a mentor, or take on other extra duties that may come up. Some of our teachers coach every season and teach six different classes a day."

- Administrator B stated, "We need teachers who are invested in our culture and our school. If they are dedicated to teaching and to our students I am able to work with them on the content. There are certain things you can't teach that make a classroom successful and those qualities are hard to find-you have to capture those people who will invest in what you are building to make your school successful."

\section{Domain 4: Professional Responsibilities}

- Opportunities

- Small class sizes

- Challenges

- Limited resources and funding

- Access to quality professional development

- Teacher candidate pool, recruiting, hiring, and retaining effective teachers

According to Nicosia (2017), "Inequitable school funding to rural districts and the greater political influence of non-rural education advocates — because of their sheer size contributes to furthering inequity." 


\section{Domain 4: Professional Responsibilities}

\section{- Professional Development}

- Administrator B responded, "Funding, the ability to recruit and maintain quality teachers in a competitive market, and professional learning opportunities are areas that are challenging for rural schools."

\section{Domain 4: Professional Responsibilities}

\section{- Teacher certification}

- Administrator A reflected on the challenges of the teacher candidate pool in rural areas, "In recent years I have posted jobs with little to no success in finding highly qualified, or even certified candidates and have resulted to recruiting invested people who will join an alternative certification program to become a teacher. Then I help to mentor them and train them in the elements of teaching as they work toward certification." 


\section{Recommendations}

- Conduct classroom observations and walk-throughs on a regular basis (minimum of monthly based on teacher performance) and provide timely and quality feedback to impact teacher effectiveness and growth.

-When conducting classroom observations and walk-throughs, focus on the following indicators: student/teacher engagement, critical thinking, relationships, classroom management, and quality assessments.

Based on the findings, implications, and the researcher's experiences as a teacher and administrator in secondary rural schools the following recommendations for effective teaching were developed:

Implementing these recommendations with fidelity will positively influence teacher effectiveness in a rural secondary public school.

\section{Recommendations}

- Provide quality professional development opportunities on instructional-based learning, but also provide opportunities for the development/awareness/enhancement of rural values.

- Refine methods of recruitment, hiring, and retention of effective teachers by creating a foundational onboarding plan containing elements of rural school demographics. 


\section{Recommendations}

- Rural school leaders should actively be involved in a networking organization specific to their demographic region such as the Missouri Advocate Rural Education Association to build instructional-based support and hear from other rural educators within the regional area.

- Creation of a collaborative network between secondary school leaders and higher education teacher preparation programs to ensure teacher candidates are aware of opportunities and challenges in rural school settings.

\section{Recommendations}

- Creation of a Grow Your Own program in rural schools to invest in graduates with a predisposition for education, providing scholarship monies as a recruitment tactic to create a larger candidate pool of quality applicants.

There is a need for further research on the area of teacher effectiveness in rural schools to help build success and student achievement in rural regions. Further research should be conducted on inequities on how the extracurricular demands and multiple responsibilities hinder student learning and quality of instruction. 
ADMINISTRATORS' PERCEPTIONS OF TEACHER EFFECTIVENESS

\section{Works Consulted}

- Arnold, M. L., Newman, J. H., Gaddy, B. B., \& Dean, C. B. (2005). A look at the condition of rural education research: Setting a direction for future research. Journal of Research in Rural Education, 20(6), 125.

- Creswell, J. W. (2014). Research design: Qualitative, quantitative, and mixed methods approaches (4th ed.). Thousands Oak, CA: SAGE.

- Danielson Group (2013). Promoting effective teaching and professional learning. Retrieved from https://www.danielsongroup.org/

- Khattri, N., Riley, K. W., \& Kane, M. B. (1997). Students at risk in poor, rural areas: A review of the research. Journal of Research in Rural Education, 13(2), 79-100.

\section{Works Consulted}

- Merriam, S. B., \& Tisdell, E. J. (2016). Qualitative research: A guide to design and implementation (4th ed.). San Francisco, CA: Joseey-Bass.

- Nicosia, M. (2017). Weigh in on new report's findings tying gap to prosperity. T74 Media. Retrieved from https://www.the74million.org/article/solving-the-rural-educationgap-experts-weigh-in-on-new-reports-findings-tying-gap-toprosperity/

- Seidman, I. (2013). Interviewing as Qualitative Research (4th ed). New York, NY: Teachers College Press.

- Waters, T., Marzano, R.J., \& McNulty, B. (2003). Balanced leadership: What 30 years of research tells us about the effect of leadership on student achievement (Working Paper). Retrieved from the California Commission on Teacher Credentialing website: https://www.ctc.ca.gov/docs/default-source/educatorprep/asc/5031rr_balanced leadership.pdf 
ADMINISTRATORS' PERCEPTIONS OF TEACHER EFFECTIVENESS

\section{References}

- For a complete list of references used to throughout the research process please contact Sarah Barmann-Smith at sbarmannsmith@albany.k12.mo.us. 
ADMINISTRATORS' PERCEPTIONS OF TEACHER EFFECTIVENESS

SECTION FIVE

CONTRIBUTION TO SCHOLARSHIP

\section{Target Journal}

The target journal for publication is the The Rural Educator. This journal focuses on the impact of policies on rural schools, funding, and finance issues related to rural schools and issues related to specific rural school populations.

\section{Rationale for this Target}

The journal's primary focus is on studies of rural education. It is my hope the research presented will provide current and aspiring administrators with a collection of research to impact their role in instructional leadership directly pertaining to rural teacher effectiveness.

\section{Outline for Proposed Contents}

\section{Detailed Abstract}

Purpose

Research Methods/Approach (setting, participants, research design, data collection, analysis)

Findings

Implications for Research and Practice

\section{Plan for Submission}

Who: The manuscript will be submitted to the online system at the The Rural Educator When: Summer 2019

How: The manuscript will be submitted electronically to https://journals.library.msstate.edu/ruraled/information/authors 


\title{
ADMINISTRATORS' PERCEPTIONS OF TEACHER EFFECTIVENESS
}

The Rural Educator requires the following:

- Current and sufficient review of literature grounds the study in rural education contexts

- Research methodology is appropriate and sufficiently described

- Data analysis and findings/results are appropriate and adequately described

- Appropriate and thorough discussion of conclusions, implications and limitations, including implications for rural education

- $\quad$ Significance of the research for rural education contexts

- Clarity of writing (syntax, style, mechanics, organization)

- Overall level of scholarship

\section{Submission Ready Journal Article}

\begin{abstract}
The purpose of this qualitative case study was to help identify administrators' perceptions of effective teaching in rural Northwest Missouri in secondary public schools in order to increase teacher and administrator effectiveness. Current members of the Northwest chapter of the Missouri Association of Secondary School Principals participated in surveys, interviews, and a focus group to collect data to find common themes and trends. These methodologies indicated effective teaching is rooted in establishing relationships, high student/teacher engagement, student growth in content, high critical thinking, good classroom management skills, and the use of well-rounded classroom observation feedback.
\end{abstract}




\section{ADMINISTRATORS’ PERCEPTIONS OF TEACHER EFFECTIVENESS}

\section{Introduction}

As the bell rings to start the day at Northview Middle/High School, students flood into the classrooms of their first hour courses to begin another day. Mr. Madison’s history students enter the room and sit in their desks, organized in rows. Each day he has a worksheet placed on every desk waiting for the students to complete when the bell rings. On many occasions Mr. Madison delivers lectures aligned to the standards on his pacing guide and incorporates stories based on travels his family has experienced or documentaries he has viewed. Formative assessments, such as quizzes and worksheets and summative unit assessments are given on a regular basis and his test scores have proven to be higher than the state average. Students generally enjoy going to $\mathrm{Mr}$. Madison's class because they think he is interesting and can relate to him.

Mrs. Jefferson's English students enter the room, giving a high five to her as they walk past the door and go to get their writing prompt from the jar in the front of the classroom. Each day they have a different activity to complete when the bell rings. On many occasions Mrs. Jefferson divides the class period into whole group instruction and collaborative group time aligned to the standards on her pacing guide. Formative assessments, such as pair, share, and report, creating YouTube videos, or blogging and summative written or oral assessments and projects are given on a regular basis and her test scores have proven to be higher than the state average. Students generally enjoy going to Mrs. Jefferson's class because they think her class is fun.

Based on the given information about both Mr. Madison and Mrs. Jefferson, what factors would identify each as an effective teacher? Does one display more effective teaching qualities than the other? 


\section{ADMINISTRATORS’ PERCEPTIONS OF TEACHER EFFECTIVENESS}

Education is constantly changing (Zhao, 2015). As society continues to advance and prepare students for the $21^{\text {st }}$ Century, the role educators play in providing effective classroom experiences are evolving. In the 1980's the role of the teacher was focused on instruction, decision making, creating a productive climate and attending to student motivation, planning lessons, addressing behaviors, and applying teaching methods in the classroom (Kindsvatter, Wilen, \& Ishler, 1988).

In May of 2013, the Missouri Department of Elementary and Secondary Education developed the Missouri Educator Evaluation System that contains a document outlining the nine teacher standards (DESE, 2017). These state standards of effective teaching focus on teachers constantly developing knowledge and skills while functioning as high-level practitioners: Standard 1- Content knowledge aligned with appropriate instruction; Standard 2- Student learning, growth and development; Standard 3Curriculum implementation; Standard 4- Critical thinking; Standard 5- Positive classroom environment; Standard 6- Effective communication; Standard 7- Student assessment and data analysis; Standard 8- Professionalism; and Standard 9- Professional collaboration (DESE, 2017). Within the nine teacher standards, there are a total of 36 quality indicators sporadically placed for the expectations of performance for effective teaching (See Appendix A). The elements that are associated with effective teaching methods, delivery, and craft are progressing as different student learners are emerging and it is the duty of the educator to serve each child's need.

Tirozzi (2001) noted, "Schools and classrooms that excite and challenge students and promote their creativity greatly support learning" (p. 436). Effective teaching has progressed and it is essential to obtain feedback from administrators to gain knowledge 


\section{ADMINISTRATORS' PERCEPTIONS OF TEACHER EFFECTIVENESS}

through research to explore the most vital qualities that produce effective teaching for students in rural Northwest Missouri. Arnold, Newman, Gaddy, and Dean (2005) pointed out that rural schools struggle to attract, recruit, and retain effective teachers (p. 4). Arnold et al. (2005) stated, "Three broad areas related to the quality of rural teachers need to be explored: (a) recruiting highly qualified teachers and inducting them effectively into rural schools; (b) providing effective teachers professional development that is aligned with research-based strategies and school improvement goals; and (c) retaining teachers in geographically isolated schools (p.18).

Khattri, Riley, and Kane (1997) echoed that the hardships and struggles rural schools face when honing in on effective teachers, and when effective teachers are hired, acquiring the ability to retain and continue to professionally develop and grow teachers' skills. There is a need to determine administrators' perspectives of effective teaching in rural Northwest Missouri secondary public schools to help determine the role administrators play as instructional leaders to help attract, retain, coach, and shape effective teachers, as it is the duty of each school district to provide all students the best education possible, no matter the location of their school building. There are opportunities in rural school systems such as smaller class sizes, building relationships, familiarity with families, and local control, but there are challenges (decreasing enrollment and transient population, limited funding and resources, and a small teacher candidate pool) that educators must face and overcome to provide effective teaching and instruction. 


\section{ADMINISTRATORS’ PERCEPTIONS OF TEACHER EFFECTIVENESS}

\section{Statement of the Problem}

\section{Problem in Practice}

Creswell (2014) stated, "The problem comes from a void in literature, and conflict in research results in the literature, topics that have been neglected in the literature; need to lift up the voice of marginalized participants; and 'real-life' problems found in the workplace, the home, the community, and so forth" (p. 20). The problem with current practice in the Northwest Missouri rural secondary public school area is the lack of gathered, informed administrators' perspectives of effective teaching among administrative groups. As the role of the administrator has shifted and instructional leadership has moved to the forefront, other responsibilities have not gone away, especially in small rural school where many instances show a single administrator in a building taking on all roles (Arnold et. al., 2005; Smith \& Addison, 2013; Tirozzi, 2001). Today's administrators are expected to focus on school culture, community outreach, being a change agent, promoting and actively using situational awareness, while providing resources, planning professional development, and being directly involved in curriculum, instruction, and assessment practices. In addition, they also must evaluate the effectiveness of teachers (Waters, Marzano, \& McNulty, 2003).

In the state of Missouri, administrators use evaluation tools that vary from district to district to assess and provide feedback to teachers based on the nine Missouri Teacher Standards (DESE, 2017a). There is a need to gather information to relay the most vital qualities effective teachers utilize from rural Northwest Missouri administrators' perspectives in order to collect information to provide supportive leadership for student and teacher success in the classroom. These perceptions will also allow administrators to 


\section{ADMINISTRATORS’ PERCEPTIONS OF TEACHER EFFECTIVENESS}

serve as effective instructional leaders, provide opportunities for the coaching of teachers to become effective or sustain effectiveness, and to retain the best teachers in rural communities.

\section{Existing Gap}

While research from Hattie (2012); Marzano, Pickering, and Pollock (2001); Wong and Wong (1998); DuFour (2006); Dagget (2014); and Rutherford (2016) addressing effective teaching, there is an existing gap in the research when looking specifically at the structure of small, rural schools and administrators' perceptions of effective teachers in secondary education. Current research does not address what rural Northwest Missouri secondary public schools, or schools of a similar demographic, need in a teacher candidate or current practitioners in order for them to thrive and for students to be successful. Khattri et al. (1997) commented, “[...] little research has been done on how to improve the qualifications and preparedness of rural educators; and the studies of rural teachers that do exist often do not describe strictly rural phenomena” (p. 91).

Much literature is based on generalizations with overall teacher effectiveness, not specific to rural demographic needs. According to Arnold et al (2005), "Identifying such interventions is difficult, however, due to a lack of high-quality research conducted in rural settings" (p. 1). Furthermore, Sherwood (as cited in Arnold et al., 2005) concluded, "Relatively few scholars are studying rural education issues, and almost no funding is available to conduct education research in specifically rural contexts" (p. 1).

\section{Purpose of the Study}

The purpose of this qualitative bounded case study is to help identify administrators' perceptions of effective teaching in rural Northwest Missouri secondary 


\section{ADMINISTRATORS' PERCEPTIONS OF TEACHER EFFECTIVENESS}

schools. Considering the demographics, needs, opportunities, and challenges of the rural setting may better help identify what administrators perceive as effective teaching specifically based on rural public school factors. According to Nicosia (2017), "Inequitable school funding to rural districts and the greater political influence of nonrural education advocates — because of their sheer size — contributes to furthering inequity." Rural schools, as opposed to urban schools, have been understudied and in many cases have not produced students who go on to get advanced degrees. Almy and Tooley (2012) discussed how in recent years effective teaching has been a hot issue for policy makers across the country and recommend that schools follow in the footsteps of others they have found that have had success in the areas of teaching and learning by focusing on strong leadership, a campus-wide commitment to improving instruction by analyzing student data and reflecting on practice, creating a collaborative environment, and building and sustaining strong teaching and learning conditions for all.

Kumari and Padhi (2014) conducted a study comparing rural and urban teacher effectiveness and found no significant effect on teacher effectiveness based on location, but remarked, "effectiveness of teachers is not only measured by his mastery over subject but also by their efficiency, competency, effective control over teaching class, leadership qualities, inter-human relations, cooperative behaviour and academic excellence" (p.27). Gao and Liu (2013) focused specifically on personality traits of teachers in their research study, as they wrote, "personality traits of effective teachers have been an important area of investigation" (p.84).

Rutherford (2016) based his research called The 23 Artisan Themes after observing more than 40,000 classrooms across the United States and developing themes 


\section{ADMINISTRATORS' PERCEPTIONS OF TEACHER EFFECTIVENESS}

honed in on the most important skills for the development of teaching. These 23 themes are broken into three areas: technical work, scientific aspects, and artistic nature (Rutherford Learning Group, 2016). Hattie (2012) discussed that expert teachers are not rooted in a singular teaching style, but are adaptable and adjust to the students and their learning in order to increase student achievement and success. Wong and Wong (1998) focused on a well-managed and succinct classroom involving high expectations, classroom routines, management, and procedures that were clearly demonstrated and communicated. Dufour (2006) deemed collaboration to be the key to success, while Daggett (2014) promoted rigor, relevance, and relationships as a means to student achievement. Experts have research-based data suggesting the most important qualities that reflect effective teaching. This study will take into consideration administrators' perceptions of effective teaching in relation to some of the rural demographics and trends unique to Northwest Missouri and other regions of similar demographic. The student population in rural schools across Missouri is declining and fluctuation in population is inconsistent based on an increased transient population (Carr \& Kefalas, 2009; Longworth, 2008). Lack of resources and funding have been challenging in rural communities and created a disparity in many classrooms compared to more urbanized communities (Christie, 2001; Giannini, 2009). These factors also contribute to a decline in recruiting and retaining teachers. The purpose of this study is to research administrators' perspectives of effective teaching in rural Northwest Missouri secondary public schools when considering the rural school setting. 


\section{ADMINISTRATORS’ PERCEPTIONS OF TEACHER EFFECTIVENESS}

\section{Research Question}

Qualitative research questions are designed to address a void in the literature by analyzing emerging themes and connections to produce thick, rich descriptions (Creswell, 2014; Merriam \& Tisdell, 2016). The overarching research question guiding this study is: What are the administrators' perceptions of effective teaching in rural Northwest Missouri secondary public schools?

\section{Conceptual Framework}

Danielson (2010) stated, 'It's not sufficient to say, 'I can't define good teaching, but I know it when I see it"” (p.38). Danielson (2013) created the Framework for Teaching which is a research-based effectiveness model divided into four domains and 22 segments of effective teaching. This framework, grounded in a constructivist view of teaching and learning, is partitioned into four domains: planning and preparation, classroom environment, instruction, and professional responsibilities (Danielson Group, 2013). The four domains are the funnels of this framework through which all effective teaching passes. Observations were conducted, collected, and scored in over 3,000 classrooms to produce data focused on effective teaching for the Danielson Framework for Teaching. The following key findings were generated: "effective teaching can be measured, balanced weights indicated multiple aspects of effective teaching, and adding a second observer increases reliability significantly more than having the same observer score an additional lesson” (Bill and Melinda Gates Foundation, 2013, p.4-5).

Danielson (2013) explained that within the framework, shown in Figure 1, there is not one domain that is more important than the other, but instead they all work together to create the most conducive learning experience for students. At the same time, it has 


\section{ADMINISTRATORS’ PERCEPTIONS OF TEACHER EFFECTIVENESS}

been noted that further research could be useful to see if there is more importance placed on one domain than another (Danielson Group, 2013). For example, observers reported that Domain 2, classroom environment, was typically more of a focus prior to Domain 3, instruction; this may be due to sequential need and prioritization rather than importance, but the model still shows how the four domains are cohesive and systemic in nature. Danielson (2010) explained effective teaching is not just what goes on in the classroom that you see when you walk into the room, but also consists of the "behind-the-scenes work of planning and other professional work, such as communicating with families and participating in a professional community" (p.36). It is important to have communication, evaluation, and feedback between teachers and administrators to ensure teacher quality consisting of a consistent definition of good teaching, a shared understanding of this definition, skilled evaluators, promoting professional development, and finding time for professional conversations (Danielson, 2010, p. 36-39). 


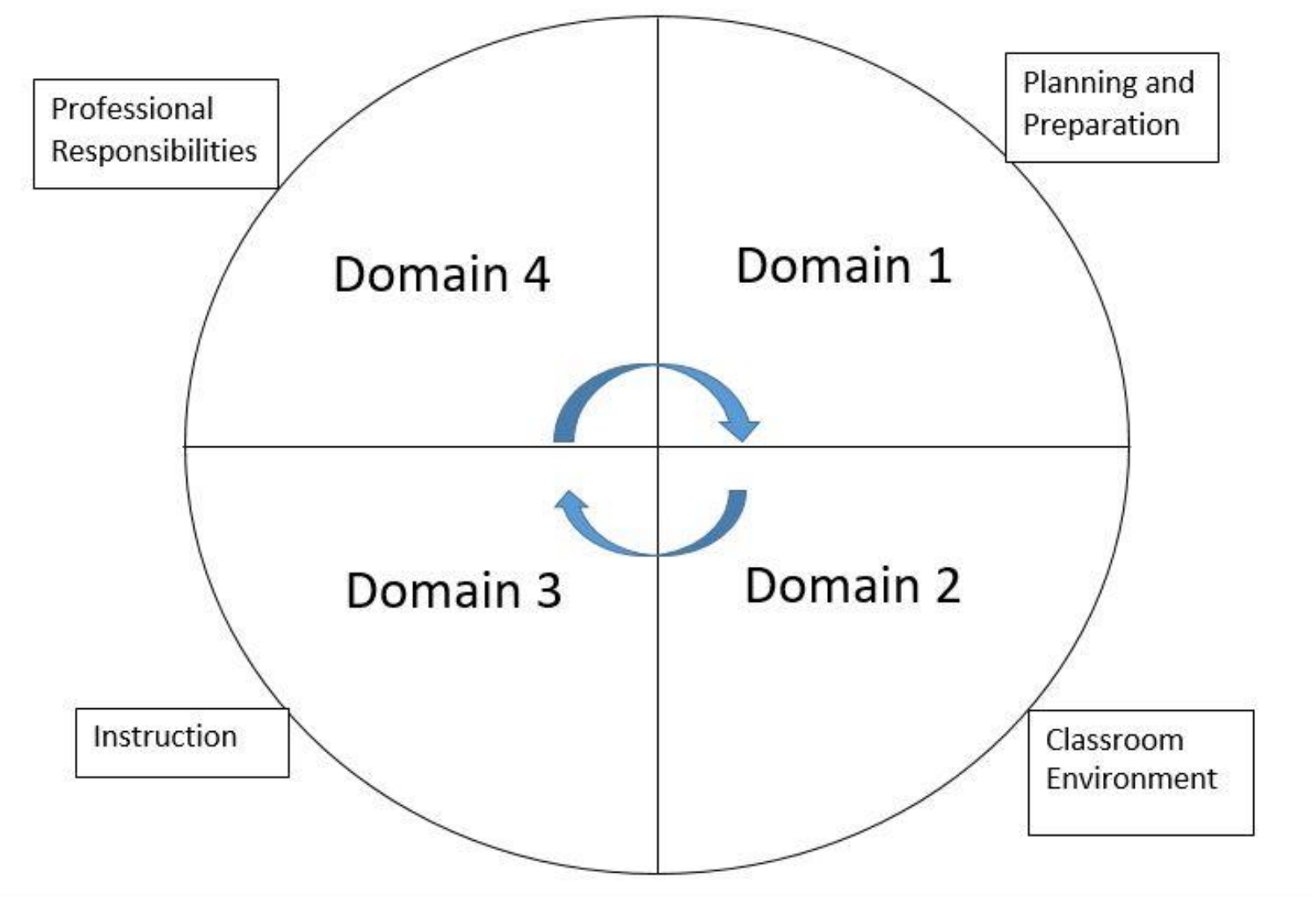

Figure 1. Danielson's Framework for Teaching depicted with the four domains that are systemic or cyclical; Domain 1: Planning \& Preparation, Domain 2: Classroom Environment, Domain 3: Instruction, and Domain 4: Professional Responsibilities. No one Domain is more important than another.

Danielson (2013) created the Framework for Teaching, a research-based effectiveness model divided into four domains and 22 segments of effective teaching. This framework, grounded in a constructivist view of teaching and learning, is partitioned into four domains: planning and preparation, classroom environment, instruction, and professional responsibilities (Danielson Group, 2013). The four domains are the funnels of this framework for which all effective teaching passes through. 
ADMINISTRATORS' PERCEPTIONS OF TEACHER EFFECTIVENESS

\section{Domain 1: Planning and Preparation}

The first domain of the Framework for Teaching is focused on planning and preparation and is divided into six subsections of emphasis (Danielson Group, 2013). Within this phase, educators show concern in content knowledge, pedagogy, demonstrating knowledge of the students, setting instructional outcomes, utilizing appropriate resources, designing coherent instruction in a variety of settings, and designing aligned assessments based on standards and student outcomes (Danielson Group, 2013).

\section{Domain 2: The Classroom Environment}

The second domain of the Framework for Teaching is focused on the classroom environment and is divided into five subsections of emphasis (Danielson Group, 2013). Within this phase, educators show concern in creating an environment of respect and rapport, establishing a culture for learning, managing classroom procedures, providing high expectations to help manage student behavior, and the physical organization of space to enhance productivity (Danielson Group, 2013).

\section{Domain 3: Instruction}

The third domain of the Framework for Teaching is focused on instruction and is divided into five subsections of emphasis (Danielson Group, 2013). Within this phase, educators show concern in communicating with students; using effective questioning, discussion, and participative techniques; engaging students in learning through structured activities; using assessment data in instruction; and demonstrating flexibility and responsiveness to student outcomes (Danielson Group, 2013). 


\section{ADMINISTRATORS’ PERCEPTIONS OF TEACHER EFFECTIVENESS}

\section{Domain 4: Professional Responsibilities}

The fourth domain of the Framework for Teaching is focused on professional responsibilities and is divided into six subsections of emphasis (Danielson Group, 2013). Within this phase, educators show concern in reflecting on teaching to grow in his or her practice; maintaining accurate records; communicating with families; participating in a professional community; growing and developing professionally; and showing professionalism through integrity, advocacy, decision-making, and ethical conduct (Danielson Group, 2013).

\section{The Framework}

Danielson (2013) explained that within the framework, shown in Figure 1, there is not one domain that is more important than the other, but instead they all work together to create the most conducive learning experience for students. Danielson (2006) believed effective teaching is not just what goes on in the classroom that you see when you walk into the room, but also consists of the "behind-the-scenes work of planning and other professional work, such as communicating with families and participating in a professional community" (p.36). It is important to have communication, evaluation, and feedback between teachers and administrators to ensure teacher quality consisting of a consistent definition of good teaching, a shared understanding of this definition, skilled evaluators, promoting professional development, and finding time for professional conversations (Danielson, 2010, 36-39). The Danielson Framework is the framework through which this study is viewed. Three key variables were explored throughout this study: effective teaching, the administrators' role as an instructional leader, and the rural 
school setting as related to instructional opportunity. These are the pillars on which this research is grounded and it is viewed through the lens of Danielson's research.

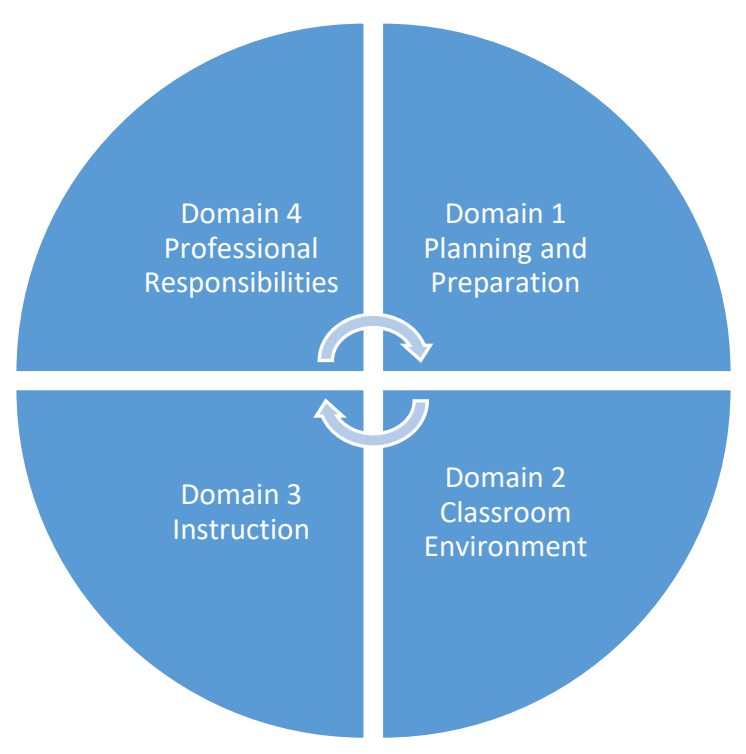

Figure 2. Danielson's Framework for Teaching depicted with the four domains that are systemic or cyclical; Domain 1: Planning \& Preparation, Domain 2: Classroom Environment, Domain 3: Instruction, and Domain 4: Professional Responsibilities. No one Domain is more important than another.

\section{Design of the Study}

As this research study was intended to measure administrators' perceptions of teacher effectiveness in rural Northwest Missouri, a qualitative case study was conducted (Creswell, 2014; Merriam \& Tisdell, 2016). Creswell (2014) described this approach as one for, "exploring and understanding the meaning individuals or groups ascribe to a social or human problem" (p.4). Merriam and Tisdell (2016) further explained, "Thus qualitative case studies share with other forms of qualitative research the search for meaning and understanding, the research as the primary instrument of data collection and analysis, an inductive investigative strategy, and the end product being richly descriptive" (p.37). 


\section{ADMINISTRATORS’ PERCEPTIONS OF TEACHER EFFECTIVENESS}

\section{Setting}

The setting for this study was specifically located in the Northwest region of Missouri designated by the Regional Professional Development Center (RPDC). The Northwest Missouri Regional Professional Development Center (NW RPDC) region five serves 61 school districts in Northwest Missouri. The average school district in this region would range from 400-550 students enrolled in Kindergarten through Twelfth grades, have a free and reduced lunch rate of 55-65\%, and have a population of primarily Caucasian students. Members of the Northwest chapter of the Missouri Association of Secondary School Principals currently practice in school districts that reside within this region. The RPDC catchment area contains fifteen counties, many containing secondary schools with rural demographics. This setting was purposeful as it allows for the demographics of the schools to be of a similar nature and many displaying rural characteristics (Merriam and Tisdell, 2016).

\section{Participants}

Participants were purposefully selected to participate in this research study. "Purposeful sampling is based on the assumption that the investigator wants to discover, understand, and gain insight and therefore must select a sample from which the most can be learned" (Merriam \& Tisdell, 2016, p.96). Current members of the Missouri Association of Secondary School Principals (MoASSP), Northwest chapter, in the Northwest RPDC region were selected to participate in a purposeful convenience sample. There are currently 88 members in the Northwest chapter of MoASSP ranging from assistant principals to recently retired principals; all were initially contacted to participate in this study. This sample was conducted as a purposeful convenience sample "based on 
ADMINISTRATORS' PERCEPTIONS OF TEACHER EFFECTIVENESS

time, money, location, availability of sites or respondents" (Merriam \& Tisdell, 2016, p.98).

\section{Data Collection Tools}

Three data collection tools were used to establish triangulation as defined by Merriam and Tisdell (2016) and Creswell (2014) to create validation and saturation. The data collection tools selected for this study began with surveys, designed with guidance from Fink (2017) composed of open ended questions, distributed online through email to current members of the MoASSP Northwest chapter. The survey utilized feedback responses on open-ended designed questions (Fink, 2017). Survey questions were constructed through the lens of the Danielson Framework (2013) and there was an overall response rate of $35 \%$.

Interviews were designed and conducted with practices employed from Seidman (2013) and Merriam and Tisdell (2016) with questions based on the Danielson Framework (2013) until categories became apparent, themes emerged, and saturation occurred. The researcher used "highly structured interviews" conducted in person, via phone, or via teleconferencing with five practicing principals (Merriam \& Tisdell, 2016, p.109).

Table 1

Interview Participant's School Population

\begin{tabular}{ll} 
Interview Participant & School Population of Building Administrator \\
\hline Administrator A & 426 \\
Administrator B & 249 \\
Administrator C & 213 \\
Administrator D & 324 \\
Administrator E & 157 \\
\hline
\end{tabular}




\section{ADMINISTRATORS’ PERCEPTIONS OF TEACHER EFFECTIVENESS}

Finally a focus group, consisting of three secondary principals and administrators from the MoASSP, was composed and structured with questions based on the Danielson Framework (2013) and methods supported by Krueger and Casey (2015), "the focus group is characterized by homogeneity but with sufficient variation among participants to allow for contrasting opinions...the guiding principle is the degree to which these factors [occupation, past use of program or service, age, gender, and/or family characteristics] will influence sharing within the group discussion" (p.81). Lincoln and Guba (1985), as referenced in Merriam and Tisdell (2016), "recommend sampling until a point of saturation or redundancy is reached" (p.101).

Table 2

Focus Group Participant's School Population

\begin{tabular}{ll} 
Focus Group Participant & School Population of Building Administrator \\
\hline Administrator F & 148 \\
Administrator G & 147 \\
Administrator H & 226 \\
\hline
\end{tabular}

\section{Data Analysis}

During the data analysis process, the researcher recorded and transcribed all responses and utilized member check of transcriptions, scrutinized responses for emerging themes from interviews and the focus group conducted through first using open coding, followed by axial coding (Creswell, 2014; Merriam \& Tisdell, 2016; Seidman, 2013). Once the data was analyzed, major categories were created, and sub-category descriptors devised. "Researchers make interpretations of the statistical results, or they interpret the themes or patterns that emerge from the data" (Creswell, 2014, p.17). The 
ADMINISTRATORS’ PERCEPTIONS OF TEACHER EFFECTIVENESS

researcher then created a table to display the findings and had the table cross-referenced to check for validity from participants (Merriam \& Tisdell, 2016; Seidman, 2013).

\section{Limitations, Delimitations, and Assumptions}

\section{Limitations}

Limitations are shortcomings, surroundings, or biases that the researcher cannot control, but that need to be mentioned in order to receive a holistic view of the study which has been conducted (Creswell, 2014). The researcher has been a member of MoASSP and an administrator in the Northwest region and has also been a secondary teacher. The roles the researcher has assumed may influence some ideation, but the researcher has been trained to refrain from allowing bias to enter into any research conducted, analyzed, or presented in this study.

\section{Delimitations}

This was a bounded case study and was conducted with the Northwest region of the RPDC in the state of Missouri (Creswell, 2014). This may limit the findings of the research given the rural area, location, and only including members of MoASSP in the region. There are no urban areas represented in this sample. Elementary level principals and administrators were not consulted in the process and may have brought differing opinions and views that may have impacted the data collected that were not represented.

\section{Assumptions}

The researcher is not familiar with all participants of the study and there are assumptions that are present. The researcher assumed participants in the case study have provided honest information and answered all interview and survey questions truthfully. It is the researcher's assumption the participants cooperated to provide quality 


\section{ADMINISTRATORS’ PERCEPTIONS OF TEACHER EFFECTIVENESS}

information to improve scholarship and practice, not for any personal reason. The researcher made the assumption the participants had prior knowledge of and responsibilities for evaluating teacher effectiveness and providing feedback to teachers in their buildings.

\section{Significance of the Study}

\section{Scholarship}

There is a gap in research on administrators' perceptions of effective teaching practices and specifically effective teaching in rural areas. This qualitative bounded case study added to that literature and helped provide the perceptions of administrators in the Northwest region of MoASSP who use a variety of different evaluation tools to observe teacher effectiveness. Teacher effectiveness and performance have a direct impact on student performance (Almy \& Tooley, 2012). Data collected from this study presented common and differing factors in qualities of teacher effectiveness.

\section{Practice}

Research collected from this study provided relevant information for the field of education. The significance of this study was to inform principals and other administrative practitioners in rural Northwest Missouri current administrators' perceptions of effective teaching in secondary classrooms. This study will be beneficial to the instructional leaders of rural Northwest Missouri to help indicate ways to coach and provide instructional leadership to impact teacher effectiveness. This study will give further insight into attracting teacher candidates and retaining current teacher practitioners by understanding administrators' perspectives of effective teaching in secondary classrooms from this region's instructional leaders. 


\section{ADMINISTRATORS’ PERCEPTIONS OF TEACHER EFFECTIVENESS}

\section{Findings}

Themes and trends surrounding the three pillars of effective teaching, the administrators' role in effective teaching, and effectiveness in rural school settings emerged through surveys, interviews, and a focus group conducted during the research. All three data collection tools were designed and constructed using the lens of the Danielson Framework for Teaching grounded in the four domains: Planning and Preparation, Classroom Management, Instruction, and Professional Responsibilities. The information gleaned and presented in the findings from this research is specific to the Northwest region of the state of Missouri and generalization of these findings should not be applied to the entire state or to other states. Administrators who participated in this study distinguished that effective teaching is rooted in all four domains throughout the Danielson Framework for Teaching.

\section{Domain 1: Planning and Preparation}

Common themes that emerged from Domain 1: Planning and Preparation as noted in Danielson's Framework for Teaching consisted of high student/teacher engagement, student learning/growth/progress in content, student performance on state assessments, and high critical thinking and depth of knowledge used in lessons. Administrator A stated, "When you see positive relationships with students; when you walk in the room and students are engaged; when test scores are satisfactory and improving; when you witness collaboration among peers- you know a teacher is effective. You see students do more critical thinking and project-based learning." Administrator E pointed out, "Our teachers collaborate during their planning process and even extend that to neighboring schools to build a network. This makes it a 'working 


\section{ADMINISTRATORS’ PERCEPTIONS OF TEACHER EFFECTIVENESS}

smarter not harder approach' for many of them." Administrator D said, "It is important for our teachers to be up-to-date on their curriculum, standards, and current practices. They need to have their lesson plans prepared and be flexible to serve our students, but also follow their pacing guides while they are planning so they are ready each day." Administrator H commented, “After each lesson, our most effective teachers realize a lesson they just presented was a huge success or conversely, a huge failure. They then build and adjust and look for the results in their students. If students are consistently engaged in a positive way and I see them differentiating for every student I know they are making gains."

\section{Domain 2: Classroom Environment}

Administrators throughout the data collection process reported creation of a positive classroom environment, building positive relationships with students, colleagues, and community, and having a passion for teaching add to effective teaching in rural schools. Several respondents mentioned qualities and characteristics of effective teachers that add to effective teaching that are difficult to teach or coach: passion, motivation, dedication, commitment, and investment. Administrator B commented, "You can tell almost immediately based on student engagement, classroom management, and the passion teachers are showing in their craft" while Administrator C added, "Effective teachers have it all- plus the extra gumption to get creative and innovative, to keep their classrooms fresh and motivate students to go the extra mile because they are."

Administrator F put it well, “Appreciating the unique rural-life values: family, community, agriculture, independence, and quality of life.” Educators are ingrained in the community, whether or not they reside where they teach, when they are part of a rural 


\section{ADMINISTRATORS' PERCEPTIONS OF TEACHER EFFECTIVENESS}

school. This awareness and appreciation extends beyond the classroom and are critical for teacher effectiveness. Administrator $\mathrm{H}$ stated, "Teachers need to extend beyond the classroom and be immersed in the community. Many of our teachers attend activities and live in our community and this speaks volumes for them with our stakeholders." These values may be foreign to some teachers if they came from a different background and they may have to be learned or adapted to in order to find success.

Building relationships is at the heart of every classroom. Administrator A commented, "Our teachers have a way of making our students feel like shining stars. They interact with them on a personal level, getting to know them outside of school- their interests and families and most of them spend time with them outside of school as coaches or sponsors." Administrator D said, "As a building we focus on building relationships with every student. We form a list of students who may be 'at-risk' and our teachers make a commitment to intentionally build relationships with them so each student has a sense of belonging. If a student is not plugged in at school, learning will not take place.”

\section{Domain 3: Instruction}

Instruction was frequently noted by administrators when discussing teacher effectiveness, specifically high student/teacher engagement, student learning/growth/progress in content, student performance on state assessments, high critical thinking and depth of knowledge used in lessons, and individualized instruction. Administrator G reported, “Cognitive engagement of students, level of problem solving/critical thinking, motivation of students in the classroom, teachers ability to check for understanding during the lesson for the whole group and individuals enhancing 


\section{ADMINISTRATORS' PERCEPTIONS OF TEACHER EFFECTIVENESS}

the classroom experience for students." While Administrator H rephrased and added, “Student engagement, building upon students' learning strengths and needs, problem solving and critical thinking, positive motivation and relation building. I look for engagement and signs of curiosity and grit. I want to see students involved and taking risks and I want to see a teacher facilitating those interactions." Administrator A responded, "I always talk to students about the instruction they receive- they will tell you. In an effective classroom, the students drive the conversation. The students demonstrate learning through their work, questions, participation, and passion.” Administrator B stated, "My effective teachers are like a well-oiled machine. It's obvious the students know the expectations of the classroom, the content is being delivered in an engaging method, and all are focused on the daily lesson plan."

Administrators understood the value in being instructional leaders and the need for giving frequent, immediate feedback in order to help teacher grow in the area of instruction. In order to do this, building administrators conduct classroom observations and walk throughs on a regular basis, typically monthly, to provide feedback to teachers. The state of Missouri has nine teacher standards, with 36 indicators designed to focus on effective teaching. In order to focus on specific indicators, administrators use "look fors" during their classroom walk-throughs or observations. Participants reported that most performed classroom walk-throughs or observations either daily or monthly, while others said they struggle to find time to get into classrooms and are unable to perform those duties as often as they would like. After reviewing the data collected, five common themes emerged during discussions revolved around the "look fors" or focus indicators 


\section{ADMINISTRATORS’ PERCEPTIONS OF TEACHER EFFECTIVENESS}

for the administrators who participated in the study: high student/teacher engagement, critical thinking, positive relationships, classroom management, and quality assessments.

For most, "look fors" were determined by the staff by practices of shared leadership and through discussions and conversations at the building or district levels. Administrator I responded, "We as a staff had a discussion about what should be seen in the classroom and then decided on what our 'look fors' should be." Others reported that the administrators decided which indicators to select or that the "look fors" were based on building or district goals that were determined by a leadership team. While some used their evaluation system to select the indicators for them to focus on. Administrator C stated, "Through the previous years weaknesses on MAP and EOC scores. Sometimes it is based on the teacher's professional development plan and the teacher's weaknesses or areas of growth."

\section{Domain 4: Professional Responsibilities}

The four overall categories within Domain 4: Professional Responsibilities were teacher characteristics, opportunities and challenges, professional development, and teacher certification. The common characteristics for effectiveness for rural teaching were a passion for teaching, dedication, flexibility, and the ability to take on multiple responsibilities and teach several different classes. Administrator E said, "Rural schools need a person who can not only lead a classroom, but someone who can contribute in other ways and be more than just a teacher- they need to also be a coach, a class sponsor, a mentor, or take on other extra duties that may come up. Some of our teachers coach every season and teach six different classes a day." Administrator B stated, "We need teachers who are invested in our culture and our school. If they are dedicated to teaching 


\section{ADMINISTRATORS' PERCEPTIONS OF TEACHER EFFECTIVENESS}

and to our students I am able to work with them on the content. There are certain things you can't teach that make a classroom successful and those qualities are hard to find- you have to capture those people who will invest in what you are building to make your school successful.”

Opportunities and challenges exist in every school setting, but some are more specific to the rural school setting. Several administrators mentioned there are more possibilities for effectiveness due to the small class sizes that rural districts tend to provide with a smaller enrollment. Effective teachers in rural settings would also need to be able to overcome challenges like limited resources and funding for certain items they may be interested in for their classrooms and access to quality professional development. Administrators also mentioned they have seen challenges in the teacher candidate pool when recruiting and hiring and they are also having a hard time retaining effective teachers. Administrator B responded, "Funding, the ability to recruit and maintain quality teachers in a competitive market, and professional learning opportunities are areas that are challenging for rural schools." Administrator D stated, "Students are harder to handle because they are used to being entertained because of technology and other devices. I think this boils down to the individual teacher and their ability to adapt to the changing needs of students. Students today are very different than they were twenty years ago." Administrator A reflected on the challenges of the teacher candidate pool in rural areas, "In recent years I have posted jobs with little to no success in finding highly qualified, or even certified candidates and have resulted to recruiting invested people who will join an alternative certification program to become a teacher. Then I help to mentor them and train them in the elements of teaching as they work toward certification." 


\section{ADMINISTRATORS’ PERCEPTIONS OF TEACHER EFFECTIVENESS}

Administrator C shared, "There is a gap in teaching style, risk taking, and instructional practices between our veteran teachers and our green teachers who are instructing our students. They are across the board on instruction and some of our students feel their education is not rigorous or is lacking." Administrator H commented, "Some of my teachers are overwhelmed by the work load and extra obligations they are working to get through the day. They have several preps and extra responsibilities and the expectations that were once in place are not always held to the standard they were when I first started in the classroom." Few positive shifts were mentioned, but did not emerge as common themes: risk taking new ideas, professional development opportunities, and more focused on building relationships. Administrator B stated, "I have seen our teachers taking risks and working to build more relationships with students. They value professional development and want to be involved in our school and community."

Administrators recognized the need to be instructional leaders in their buildings and districts and continually work to grow and improve. Many set goals to give more timely and quality feedback after classroom observations, work to model and lead staff in instructional strategies, focus on curriculum, work on time management, keep up to date on Stem and technology for the classroom and education, and to stay current on educational topics to share with staff members. Participants talked about struggling to find time to balance it all and that they had several things they wanted to give more time to, but it always seemed that something had to give or be put on the "back burner." 


\section{ADMINISTRATORS’ PERCEPTIONS OF TEACHER EFFECTIVENESS}

\section{Implications for Research and Practice}

By using valid data collection tools to provide triangulation and saturation, themes emerged to recommend the following implications to practitioners in secondary rural public schools. Data was gathered from surveys, interviews, and a focus groups which consisted of participants who were members of the Northwest chapter of the Missouri Association of Secondary School Principals. The findings of this study were based on the three pillars of effective teaching, effectiveness in rural school settings, and the administrators' role in teacher effectiveness viewed through the lens of Danielson's Framework for Teaching and the four domains: planning and preparation, classroom management, instruction, and professional responsibility.

Administrators could tell teachers were effective when they were able to build relationships, have high student/teacher engagement, show student learning/growth/progress, perform well on state assessments, plan lessons with high critical thinking/depth of knowledge, and exhibit good classroom management. When considering teacher effectiveness in the rural setting, there was more to effectiveness than the four domains Danielson's Framework provides; there are rural values that extend beyond the classroom that impact effectiveness. Administrators have a role in effectiveness and communicate much of this through classroom observations and walkthroughs where they "look for" indicators of effective teaching. The main indicators administrators are looking for are student engagement, critical thinking, positive relationships, classroom management, and quality assessments. All four domains of Danielson's Framework for Teaching were present throughout the findings of this study, but the one that was least referenced was planning and preparation. 


\section{ADMINISTRATORS’ PERCEPTIONS OF TEACHER EFFECTIVENESS}

In conclusion, this study had a relatively small sample size, as it was limited to one chapter of the MoASSP and could have extended to the whole association to get a full representation of the state. This study could have also looked at several different rural areas across the country, as this specific study was limited to one region, in one state. Based on the findings and implications, there are certain qualities and characteristics that help teachers to be more effective in rural secondary public schools: flexibility, multi-tasking, community relations, rural values. As teacher candidates are declining, one role administrators will need to develop is recruiting, hiring, and retention methods to ensure teacher effectiveness for rural schools. There is a need for further research on the area of teacher effectiveness in rural schools to help build success and student achievement in rural regions. Further research should be conducted on inequities on how the extracurricular demands and multiple responsibilities hinder student learning and quality of instruction.

\section{Recommendations for Effective Teaching in Secondary Rural Schools}

Based on the findings, implications, and the researcher's experiences as a teacher and administrator in secondary rural schools the following recommendations for effective teaching were developed:

- Conduct classroom observations and walk-throughs on a regular basis (minimum of monthly based on teacher performance) and provide timely and quality feedback to impact teacher effectiveness and growth.

- When conducting classroom observations and walk-throughs, focus on the following indicators: student/teacher engagement, critical thinking, relationships, classroom management, and quality assessments. 
ADMINISTRATORS' PERCEPTIONS OF TEACHER EFFECTIVENESS

- Provide quality professional development opportunities on instructional-based learning, but also provide opportunities for the development/awareness/enhancement of rural values.

- Refine methods of recruitment, hiring, and retention of effective teachers by creating a foundational onboarding plan containing elements of rural school demographics.

- Rural school leaders should actively be involved in a networking organization specific to their demographic region such as the Missouri Advocate Rural Education Association to build instructional-based support and hear from other rural educators within the regional area.

- Creation of a collaborative network between secondary school leaders and higher education teacher preparation programs to ensure teacher candidates are aware of opportunities and challenges in rural school settings.

- Creation of a Grow Your Own program in rural schools to invest in graduates with a predisposition for education, providing scholarship monies as a recruitment tactic to create a larger candidate pool of quality applicants.

Implementing these seven recommendations with fidelity will positively influence teacher effectiveness in a rural secondary public school.

\section{Summary}

The world of education is constantly changing (Zhao, 2015). Due to transformations in our society and advancements needed to provide for all students, it is important to collect and reflect on administrators' perspectives of teacher effectiveness to help inform the instructional leadership practices and the hiring and retention challenges 


\section{ADMINISTRATORS’ PERCEPTIONS OF TEACHER EFFECTIVENESS}

rural districts face. As educators it is important that quality and effectiveness are displayed at a high level and students are prepared for college or the workplace upon graduation. In order to do this, teacher effectiveness needs to be examined to provide equity in classrooms.

Teachers are at the frontline and have the most impact on student learning and achievement (Almy \& Tooley, 2012). Administrators must hire effective teachers, coach effective teachers, give quality feedback to ensure effective teaching, and retain effective teachers, but first there must be a consistent understanding of what qualifiers point toward effectiveness. This study captured the administrators' perceptions of teacher effectiveness in rural Northwest Missouri at the secondary level. 
ADMINISTRATORS' PERCEPTIONS OF TEACHER EFFECTIVENESS

SECTION SIX: SCHOLARLY PRACTITIONER REFLECTION

Mihelic, Lipicnik, and Tekavcic's (2010) define leadership as the art of persuading a follower to want to do the tasks the leader sets as goals (p. 32). Northouse (2016) defines leadership as "a process whereby an individual influences a group of individuals to achieve a common goal" (p. 6). Leadership may be described as a trait, a skill, or a behavior, but some lend themselves to displaying leadership through their passion, service, and desire to make a positive impact. As Kotter (1990/2011) stated, one must "combine strong leadership and strong management and use each to balance the other" (p. 37). When incorporating Kotter's idea of management versus leadership, one must embody an effective balance between both creating an environment that is structurally flourishing and relationally enjoyable for all team members. Administrators are instructional leaders of the school buildings in which they serve and must work to promote effective teaching to impact student learning.

\section{Influence of Dissertation on Educational Leadership}

My passion for education comes from the process of learning and essentially focusing on helping others understand their learning path to success. Lei, Gorelick, Short, Smallwood, and Wright-Porter (2011) point out that as part of a cohort, "more cooperative learning, peer teaching, and student-led discussions take place and that a group of supportive learners with similar goals" are created (p. 500); being a learner, as proven to be my top strength as noted by the Gallup (2010) Strength Quest, is beneficial to a group and a collaborative team by having the motivation to learn and be successful. I am proud to be a member of Cohort $\mathrm{X}$ through the University of Missouri and I am also proud to be a leader of what I would consider a cohort of educators, dedicated to positively impacting students attending Albany R-III School District. 


\section{ADMINISTRATORS’ PERCEPTIONS OF TEACHER EFFECTIVENESS}

Being a servant leader is about creating value for community, empowering others, and behaving ethically (Northouse, 2016). The value in serving others and getting it right by listening, being empathetic, providing clarity, and surrounding yourself with those better than you are pillars on which I build. Leadership has changed over the years and will continue to change; we need to be the leaders we would like to work for and inspire others to become leaders who will help to do the same.

When focusing my dissertation and learning on administrators' perceptions of effective teaching, I wanted to help current and future leaders concentrate on the impact instructional leadership has on classroom practices. I have always strived to get better every day and communicate that to those around me in hope I can model and influence them to do the same. Challenging others to take tasks head-on and perform at the highest level of their ability is reflected many times in our behavior. By building relationships and rapport with our staff and students, we are able to model what we as instructional leaders are looking for in the classroom. Wlodkowski (2008) as cited in Merriam and Bierema (2014), stated, "'If something can be learned, it can be learned in a motivating manner...every instructional plan also needs to be a motivational plan"' (p.156). In rural schools we need to be attuned to the rural values that our essential to our stakeholders: family, community, agriculture, independence, and quality of life.

\section{Influence of Dissertation on Scholarly Practice}

I would describe this dissertation experience as a period of transformative learning in my life (Merriam \& Bierema, 2014). I had taught high school English for nine years and then became an elementary principal. Never did I dream I would be working with preschool-5th grade students, but a job opened in my husband's rural hometown and I jumped at the opportunity. When this opportunity presented itself, I 


\section{ADMINISTRATORS' PERCEPTIONS OF TEACHER EFFECTIVENESS}

knew I had a lot of learning to do- as I had no experience in an elementary building since I had attended school in one myself and I had never lived in a rural community. The two years serving as principal were so rewarding and transformative not only to my educational perspectives, but my outlook and thinking on the way I viewed life in general. I was learning a new culture and taking in a new set of values that exists that I had never been exposed to, and now I was fully immersed in rural living. At the same time, I was beginning a doctoral program that was opening my eyes to a new way to view leadership, diversity, ethics, policy, and learning.

As Clark (1993) stated, "transformational learning shapes people; they are different afterward, in ways both they and others can recognize" (Merriam \& Bierema, 2014, p. 82). I was learning how to be an administrator, but I was also learning a world of elementary school that I had never been a part of in rural Missouri where I had never lived. I was on a new learning journey and experiencing students excited to be at school, skipping down the hallway, reaching out a helping hand, helping kids complete service projects and learning the "habits" within themselves to help leadership skills emerge, all while learning about a new culture scared of diversity, realizing how bad the bruises of abuse hurt our students, and fighting the battle of cancer with a seven-year-old student and losing. I knew after nine years of being a teacher that I had the desire to become an administrator, but due to many transformative experiences that I have had through this dissertation process, I now know that this was the right path for me. As Kegan (2000) put it, "transformative learning--learning that 'changes how we know"' (Merriam \& Bierema, 2014, p. 84). 


\section{ADMINISTRATORS’ PERCEPTIONS OF TEACHER EFFECTIVENESS}

\section{Conclusion}

This dissertation process has helped me to realize that I see the world differently than I once did. I am always asking different questions and looking at things through different frames, lenses, paradigms, and views that I did not appreciate prior to this experience. I have not only gained knowledge and insight, but also experiences and relationships that have helped me grow as an educational leader. I am already seeing the results and impact of this journey in my daily practice and will continue to engage in the skills I have acquired in my future practices. Each day I take on the challenge to serve our teachers by being an instructional leader focused on effective teaching in a rural demographic, while charging our students with following their dreams without being limited by their zip code. 


\section{ADMINISTRATORS’ PERCEPTIONS OF TEACHER EFFECTIVENESS}

\section{Introduction}

\section{Appendix A}

The Missouri Teacher Standards convey the expectations of performance for professional teachers in Missouri. The standards are based on teaching theory indicating that effective teachers are caring, reflective practitioners and life-long learners who continuously acquire new knowledge and skills and are constantly seeking to improve their teaching practice to provide high academic achievement for all students. Thus these standards recognize that teachers continuously develop knowledge and skills. Therefore the Missouri Teacher Standards employ a developmental sequence to define a professional continuum that illustrates how a teacher's knowledge and skills mature and strengthen throughout the career. Teaching professionals are expected to supply good professional judgment and to use these standards to inform and improve their own practice.

\section{Standard \#1 Content knowledge aligned with appropriate instruction.}

The teacher understands the central concepts, structures, and tools of inquiry of the discipline(s) and creates learning experiences that make these aspects of subject matter meaningful and engaging for all students. [SB 291 Section 160.045.2 (3) The teacher is prepared and knowledgeable of the content and effectively maintains students' on-task behavior.]

Quality Indicator 1: Content knowledge and academic language

Quality Indicator 2: Student engagement in subject matter

Quality Indicator 3: Disciplinary research and inquiry methodologies

Quality Indicator 4: Interdisciplinary instruction

Quality Indicator 5: Diverse social and cultural perspectives

\section{Standard \#2 Student Learning, Growth and Development}

The teacher understands how students learn, develop and differ in their approaches to learning. The teacher provides learning

opportunities that are adapted to diverse learners and support the intellectual, social, and personal development of all students. [SB 291 Section 160.045.2 (1) Students actively participate and are successful in the learning process; (5) The teacher keeps current on instructional knowledge and seeks and explores changes in teaching behaviors that will improve student performance.]

Quality Indicator 1: Cognitive, social, emotional and physical development

Quality Indicator 2: Student goals

Quality Indicator 3: Theory of learning

Quality Indicator 4: Differentiated lesson design

Quality Indicator 5: Prior experiences, multiple intelligences, strengths and needs

Quality Indicator 6: Language, culture, family and knowledge of community values 


\section{ADMINISTRATORS’ PERCEPTIONS OF TEACHER EFFECTIVENESS}

\section{Standard \#3 Curriculum Implementation}

The teacher recognizes the importance of long-range planning and curriculum development. The teacher develops, implements, and evaluates curriculum based upon student, district and state standards data. [SB 291 Section 160.045 .2 (1) Students actively participate and are successful in the learning process; (2) Various forms of assessment are used to monitor and manage student learning; (3) The teacher is prepared and knowledgeable of the content and effectively maintains students' on-task behavior; (5) The teacher keeps current on instructional knowledge and seeks and explores teaching behaviors that will improve student performance.]

Quality Indicator 1: Implementation of curriculum standards

Quality Indicator 2: Lessons for diverse learners

Quality Indicator 3: Instructional goals and differentiated instructional strategies

\section{Standard \#4 Critical Thinking}

The teacher uses a variety of instructional strategies and resources to encourage students' critical thinking, problem solving, and performance skills. [SB 291 Section 160.045.2 (1) Students actively participate and are successful in the learning process.]

Quality Indicator 1: Instructional strategies leading to student engagement in problem-solving and critical thinking

Quality Indicator 2: Appropriate use of instructional resources to enhance student learning

Quality Indicator 3: Cooperative, small group and independent learning

\section{Standard \#5 Positive Classroom Environment}

The teacher uses an understanding of individual/group motivation and behavior to create a learning environment that encourages active engagement in learning, positive social interaction, and self-motivation. [SB 291 Section 160.045 .2 (3) The teacher is prepared and knowledgeable of the content and effectively maintains students' on-task behavior; (5) The teacher keeps current on instructional knowledge and seeks and explores changes in teaching behaviors that will improve student performance.]

Quality Indicator 1: Classroom management techniques

Quality Indicator 2: Management of time, space, transitions, and activities

Quality Indicator 3: Classroom, school and community culture

\section{Standard \#6 Effective Communication}

The teacher models effective verbal, nonverbal, and media communication techniques with students, colleagues and families to foster active inquiry, collaboration, and supportive interaction in the classroom. [SB 291 Section 160.045 .2 (4) The teacher uses professional communication and interaction with the school community; (6) The teacher acts as a responsible professional in the overall mission of the school.]

Quality Indicator 1: Verbal and nonverbal communication

Quality Indicator 2: Sensitivity to culture, gender, intellectual and physical differences

Quality Indicator 3: Learner expression in speaking, writing and other media

Quality Indicator 4: Technology and media communication tools

Missouri Teacher Standards 


\section{Standard \#7 Student Assessment and Data Analysis}

The teacher understands and uses formative and summative assessment strategies to assess the learner's progress and uses both classroom and standardized assessment data to plan ongoing instruction. The teacher monitors the performance of each student, and devises instruction to enable students to grow and develop, making adequate academic progress. [SB 291 Section 160.045 .2 (2) Various forms of assessment are used to monitor and manage student learning; (5) The teacher keeps current on instructional knowledge and seeks and explores changes in teaching behaviors that will improve student performance.]

Quality Indicator 1: Effective use of assessments

Quality Indicator 2: Assessment data to improve learning

Quality Indicator 3: Student-led assessment strategies

Quality Indicator 4: Effect of instruction on individual/class learning

Quality Indicator 5: Communication of student progress and maintaining records

Quality Indicator 6: Collaborative data analysis

\section{Standard \#8 Professionalism}

The teacher is a reflective practitioner who continually assesses the effects of choices and actions on others. The teacher actively seeks out opportunities to grow professionally in order to improve learning for all students. [SB 291 Section 160.045.2 (2) Various forms of assessment are used to monitor and manage student learning; (5) The teacher keeps current on instructional knowledge and seeks and explores changes in teaching behaviors that will improve student performance; (6) The teacher acts as a responsible professional in the overall mission of the school.]

Quality Indicator 1: Self-assessment and improvement

Quality Indicator 2: Professional learning

Quality Indicator 3: Professional rights, responsibilities and ethical practices

\section{Standard \#9 Professional Collaboration}

The teacher has effective working relationships with students, parents, school colleagues, and community members. [SB 291 Section 160.045 .2 (4) The teacher uses professional communication and interaction with the school community; (6) The teacher acts as a responsible professional in the overall mission of the school.]

Quality Indicator 1: Induction and collegial activities

Quality Indicator 2: Collaborating to meet student needs

Quality Indicator 3: Cooperative partnerships in support of student learning 
The Professional Continuum of the Missouri Teacher: The following descriptions apply to all indicators found in the standards:

\begin{tabular}{|c|c|c|c|c|}
\hline $\begin{array}{l}\text { Candidate: \#C\#) This level } \\
\text { describes the performance } \\
\text { expected of a potential teacher } \\
\text { preparing to enter the } \\
\text { profession and is enrolled in an } \\
\text { approved educator preparation } \\
\text { program at a college, } \\
\text { university, or state-approved } \\
\text { alternate pathway. Content } \\
\text { knowledge and teaching skills } \\
\text { are being developed through a } \\
\text { progression of planned } \\
\text { classroom and supervised } \\
\text { clinical experiences. }\end{array}$ & $\begin{array}{l}\text { Emerging Teacher: \#E\#) This } \\
\text { level describes the } \\
\text { performance expected of a } \\
\text { new teacher as they enter } \\
\text { the profession or a practicing } \\
\text { teacher in a new assignment. } \\
\text { The base knowledge and } \\
\text { skills are applied as they } \\
\text { begin to teach and advance } \\
\text { student growth and } \\
\text { achievement in their } \\
\text { classroom. }\end{array}$ & $\begin{array}{l}\text { Developing Teacher: \#D\#) } \\
\text { This level describes the } \\
\text { performance expected of a } \\
\text { teacher early in their } \\
\text { assignment with the teaching, } \\
\text { content, knowledge, and skills } \\
\text { that he/she possesses } \\
\text { continually developing as } \\
\text { they encounter new } \\
\text { experiences and expectations } \\
\text { in the classroom, school, } \\
\text { district, and community while } \\
\text { they continue to advance } \\
\text { student growth and } \\
\text { achievement. }\end{array}$ & $\begin{array}{l}\text { Proficient Teacher: \#P\#) This } \\
\text { level describes the } \\
\text { performance expected of a } \\
\text { career, professional teacher } \\
\text { who continues to advance } \\
\text { his/her knowledge and skills } \\
\text { while consistently advancing } \\
\text { student growth and } \\
\text { achievement. }\end{array}$ & $\begin{array}{l}\text { Distinguished Teacher: \#S\#) } \\
\text { This level describes the career, } \\
\text { professional teacher whose } \\
\text { performance exceeds } \\
\text { proficiency and who } \\
\text { contributes to the profession } \\
\text { and larger community while } \\
\text { consistently advancing student } \\
\text { growth and achievement. The } \\
\text { Distinguished Teacher serves as } \\
\text { an educational leader in the } \\
\text { school, district, and the } \\
\text { profession. }\end{array}$ \\
\hline $\begin{array}{l}\text { Indicator Terminology: } \\
\text { - } \quad \text { Demonstrate knowledge } \\
\text { - } \quad \text { Can create/implement } \\
\text { - } \quad \text { Understand/reflect } \\
\text { - } \quad \text { Aware of/recognize } \\
\text { - } \text { Observe/identify } \\
\text { - } \text { Develop ability to } \\
\text { - } \quad \text { Describe/ explain }\end{array}$ & $\begin{array}{l}\text { Indicator Terminology: } \\
\text { - Demonstrate } \\
\text { - } \text { Communicate } \\
\text { - Identify/select } \\
\text { - Use/implement } \\
\text { - } \text { Develop/create } \\
\text { - Facilitate } \\
\text { - Explore/learn } \\
\text { - Apply }\end{array}$ & $\begin{array}{l}\text { Indicator Terminology: } \\
\text { - Incorporate } \\
\text { - Apply } \\
\text { - Engage } \\
\text { - } \text { Develop/design } \\
\text { - Actively participate } \\
\text { - } \text { Realize } \\
\text { - Implement } \\
\text { - } \text { Advance }\end{array}$ & $\begin{array}{l}\text { Indicator Terminology: } \\
\text { - Expand/engage } \\
\text { - } \text { Analyze/Assess } \\
\text { - } \text { Adjust } \\
\text { - } \text { Display/Present } \\
\text { - Enable/assist } \\
\text { - } \text { Build } \\
\text { - } \text { Anticipate } \\
\text { - Establish/select }\end{array}$ & $\begin{array}{l}\text { Indicator Terminology: } \\
\text { - Mentor/Model } \\
\text { - } \text { Lead/share } \\
\text { - } \text { Connect/promote } \\
\text { - Employ } \\
\text { - } \text { Contribute } \\
\text { - } \text { Cultivate/Foster } \\
\text { - } \text { Research }\end{array}$ \\
\hline \multicolumn{5}{|c|}{ Data Points established for each level of the Professional Continuum help define or give meaning to the Indicator Terminology } \\
\hline
\end{tabular}

\section{Coding of standards:}

First Number= the \# of the standard

Second letter = the developmental category of the teacher (C=Candidate; $\mathrm{N}=\mathrm{New}$; $\mathrm{D}=$ Developing; $\mathrm{P}=$ Proficient; $\mathrm{S}=$ Distinguished)

Third \# = the sequential \# of the quality indicator for that teaching category in that standard

[Example 1D4 = Standard \#1; Developing Teacher; Quality Indicator 4]

\section{Missouri Teacher Standards}




\section{Appendix B}

Survey, Interview, and Focus Group Questions

1. Tell me about your educational experience.

a. Educational Background

b. Work Experience

c. Years as an administrator

d. Current role and duties

2. How often do you conduct classroom observations?

3. What are your look fors in the classroom?

4. How do you determine what you look for in the classroom?

5 . What factors contribute to effective teaching?

6. How do you know when a teacher is an effective teacher?

7. Have you seen any shifts in teacher effectiveness during your tenure? 
ADMINISTRATORS' PERCEPTIONS OF TEACHER EFFECTIVENESS

Appendix C

INFORMED CONSENT

\section{Case Study:}

I will research administrators' perceptions of teacher effectiveness in rural Northwest Missouri secondary public school settings.

\section{Principal investigator:}

Sarah Barmann-Smith

\section{Institute:}

Northwest Missouri State University

University of Missouri Columbia

\section{Introduction:}

While some research and professional writing address what teacher effectiveness, administrators' perceptions in rural Northwest Missouri have not been addressed or explored. As the role of the administrator has shifted and instructional leadership has moved to the forefront, other responsibilities have not gone away, especially in small rural schools where many times there is a single administrator (Arnold et. al., 2005; Smith \& Addison, 2013; Tirozzi, 2001).

\section{Background information:}

The world of education is constantly changing (Zhao, 2015). Due to transformations in our society and advancements needed to provide for all students, it is important to collect and reflect on administrators' perspectives of teacher effectiveness to help inform the instructional leadership practices and the hiring and retention challenges rural districts face. As educators it is important that quality and effectiveness are displayed at a high level and students are prepared for college or the workplace upon graduation. In order to do this, teacher effectiveness needs to be examined to provide equity in classrooms. Teachers are at the frontline and have the most impact on student learning and achievement (Almy \& Tooley, 2012). Administrators must hire effective teachers, coach effective teachers, give quality feedback to ensure effective teaching, and retain effective teachers, but first there must be a consistent understanding of what qualifiers point toward effectiveness. This study produced insight into administrators' perceptions of teacher effectiveness in the Northwest Missouri region at the secondary level.

\section{Purpose of this research study:}

The purpose of this qualitative bounded case study is to help identify administrators' perceptions of effective teaching in rural Northwest Missouri secondary schools. Almy and Tooley (2012) discussed how in recent years effective teaching has been a hot issue for policy makers across the country and recommend that schools follow in the footsteps of others they have found that have had success in the areas of teaching and learning by 
focusing on strong leadership, a campus-wide commitment to improving instruction by analyzing student data and reflecting on practice, creating a collaborative environment, and building and sustaining strong teaching and learning conditions for all.

\section{Procedure:}

Participants will either participate in a one-on-one interview or in a focus group setting with the researcher. There will be a series of questions presented to the participants by the researcher that facilitates a discussion of their experience with effective teaching practices and procedures. Participants answers will be recorded and used by the researcher.

\section{Possible risks or benefits:}

There is no risk involved in this study except your valuable time. This research has the potential of having an impact on secondary rural public school education.

\section{Right of refusal to participate and withdrawal:}

You are free to choose to participate in the study. You may also withdraw any time from the study. You may also refuse to answer some or all the questions if you do not feel comfortable with the questions.

\section{Confidentiality:}

Any information you provide will remain confidential. Nobody except the principal investigator will have an access to it. Your name and identity will also not be disclosed at any time.

\section{Available sources of information:}

If you have any further questions you may contact Dr. Carole Edmonds (cake@nwmissouri.edu), the researcher's advisor.

\footnotetext{
AUTHORIZATION:

I have read and understand this consent form, and I volunteer to participate in this research study. I understand that I will receive a copy of this form. I voluntarily choose to participate, but I understand that my consent does not take away any legal rights in the case of negligence or other legal fault of anyone who is involved in this study. I further understand that nothing in this consent form is intended to replace any applicable Federal, state, or local laws.

If you have any further questions I can answer, please contact me.

Sarah Barmann-Smith

207 South $7_{\text {th }}$ Street

Albany, Missouri 64402

816-590-5433

sabcn2@mail.missouri.edu

You may also contact the Campus Institutional Review Board if you have questions about your rights, concerns, complaints, or comments as a research participant. You can contact the Campus Institutional Review Board directly by telephone or email to voice or solicit any concern, questions, input, or complaints about the research study.

483 McReynolds Hall

Columbia, Missouri 65211

573-882-9585

E-Mail: umcresearchcirb@missouri.edu

Website: http://www.research.missouri.edu/cirb/index.htm
} 
ADMINISTRATORS' PERCEPTIONS OF TEACHER EFFECTIVENESS

\section{References}

Almy, S. \& Tooley, M. (2012). Building and sustaining talent: Creating conditions in high-poverty schools that support effective teaching and learning. The Education Trust. p.1-16.

Arnold, M. L., Newman, J. H., Gaddy, B. B., \& Dean, C. B. (2005). A look at the condition of rural education research: Setting a direction for future research. Journal of Research in Rural Education, 20(6), 1-25.

Balkar (2015). Defining an empowering school culture: Teacher perceptions. Issues in Educational Research, 25(3), 205-225.

Bardach, E. (2012). A practical guide for policy analysis: The eighfold path to more effective problem solving ( $4^{\text {th }}$ ed.). Thousand Oaks, CA: SAGE.

Barley, Z.A., \& Beesley, A.D. (2007). Rural school success: What can we learn? Journal of Research in Rural Education, 22(1), 1-16.

Baum, K., \& Krulwich, D. (2016). The Artisan Teaching Model for Instructional Leadership : Working Together to Transform Your School. Alexandria, Virginia: ASCD.

Bill \& Melinda Gates Foundation. (2013). Ensuring fair and reliable measures of effective teaching: Culminating findings from the MET project's three-year study. Retrieved at http://files.eric.ed.gov/fulltext/ED540958.pdf

Bolman, L. G., \& Deal, T. E. (2013). Reframing organizations: Artistry, choice, \& leadership (5th ed.). San Francisco, CA: Jossey-Bass. 


\section{ADMINISTRATORS’ PERCEPTIONS OF TEACHER EFFECTIVENESS}

Burns, W. R. T., \& DiPaola, M. F. (2013). A study of organizational justice, organizational citizenship behavior, and student achievement in high schools. American Secondary Education, 42(1), 4-23.

Carr, P.J. \& Kefalas, M.J. (2009). Hollowing Out the Middle: The Rural Brain Drain and What it Means for America. Boston: Beacon Press.

Christie, K. (2001). Stateline-the rural bellwether. Phi Delta Kappan, 82(6), 425.

Retrieved from https://www.questia.com/library/journal/1G170910816/statelinethe-rural-bellwether

Coe, R., Aloisi, C., Higgins, S, \& Major, L.E. (2014). What makes great teaching? Review of the underpinning research. Durham University. Project Report. Sutton Trust, London. Retrieved from http://dro.dur.ac.uk/13747/

Creswell, J. W. (2014). Research design: Qualitative, quantitative, and mixed methods approaches (4th ed.). Thousands Oak, CA: SAGE.

Dagget, W.R (2014). Rigor/relevance framework: A guide to focusing resources to increase student performance. International Center for Leadership in Education. Retrieved from http://www.leadered.com/pdf/rigor_relevance_framework_2014.pdf

Danielson, C. (2006). Teacher leadership that strengthens professional practice. Alexandria, VA: Association for Supervision and Curriculum Development. Danielson, C. (2010). Evaluations that help teachers learn. Educational Leadership, 68 (4), 35-39. Retrieved from ASCD website at: http://www.ascd.org/publications/educationalleadership/dec10/vol68/num04/Evaluations-That-Help-Teachers-Learn.aspx 


\section{ADMINISTRATORS’ PERCEPTIONS OF TEACHER EFFECTIVENESS}

Danielson Group (2013). Promoting effective teaching and professional learning. Retrieved from https://www.danielsongroup.org/

DESE (2017). Educator growth toolbox. Retrieved from: https://dese.mo.gov/educatorgrowth-toolbox/model-evaluation-system

DESE (2017a). Teacher Standards. Retrieved from: https://dese.mo.gov/educatorquality/educator-effectiveness/educator-standards/teacher-standards

DESE (2018). Administrator Standards. Retrieved from: https://dese.mo.gov/educatorquality/educator-effectiveness/educator-standards/administrator-standards

Dictionary by Merriam-Webster. (n.d). Retrieved from: https://www.merriamwebster.com/

DuFour, R. (2006). Learning by doing: A handbook for professional learning communities at work. Bloomington, Ind: Solution Tree

Fink, A. (2017). How to conduct surveys: A step-by-step guide (6th ed.). Thousands Oak, CA: SAGE.

Gao, M. \& Liu, Q. (2013). Personality traits of effective teachers represented in the narratives of american and chinese preservice teachers: A cross-cultural comparison. International Journal of Humanities and Social Science, 3(2), 84-95.

Giannini, M. (2009). National vs local funding for education: effects on growth and inequality. International Review of Applied Economics, 23(3), 367-385. http://doi.org/10.1080/02692170902811785

Goleman, D. (2011). What makes a good leader? In HBR's 10 must reads: On leadership (pp. 1-21). Boston, MA: Harvard Business School Publishing Corporation. (Reprinted from June 1996). 


\section{ADMINISTRATORS’ PERCEPTIONS OF TEACHER EFFECTIVENESS}

Hattie, J. (2003). Teachers make a difference: What is the research evidence? Australian Council for Educational Research Annual Conference on: Building Teacher Quality. (1-16). University of Auckland, New Zealand.

Hattie, J. (2012). Visible learning for teachers: Maximizing impact on learning. London: Routledge.

Haycock, K. (1998). Good teaching matters...a lot. OAH Magazine of History, 13(1), 6163.

Janis, I. L. (2005). Groupthink: The desperate drive for consensus at any cost. In J. M. Shafritz, J. S. Ott, \& Y. S. Jang (Eds.), Classics of organization theory (6th ed., pp. 185-192). Belmont, CA: Wadsworth. (Reprinted from Psychology today, pp. 43-44, 46, 74-76, 1971, Sussex Publishers, Inc.)

Kannapel, P.J., \& DeYoung, A.J. (1999). The rural school problem in 1999: A review and critique of literature. Journal of Research in Rural Education, 15(2), 67-79.

Khattri, N., Riley, K. W., \& Kane, M. B. (1997). Students at risk in poor, rural areas: A review of the research. Journal of Research in Rural Education, 13(2), 79-100.

Kindsvatter, R., Wilen, W., \& Ishler, M. (1988). The dynamics of effective teaching. New York: Longman.

Kotter, J.P. (2011). What leaders really do. In HBR's 10 must reads: On leadership (pp. 37-55). Boston, MA: Harvard Business School Publishing Corporation. (Reprinted from May 1990).

Krueger, R. A. \& Casey, A. C. (2015). Focus groups: A practical guide for applied research (5th ed). Los Angeles, CA: SAGE. 
ADMINISTRATORS' PERCEPTIONS OF TEACHER EFFECTIVENESS

Kumari, A. \& Padhi, S.K. (2014). A study of teacher effectiveness of secondary school teachers with reference to certain demographic variables. International Journal of Advanced Research, 2(12), p.26-32.

Lei, S., Gorelick, D., Short, K., Smallwood, L., \& Wright-Porter, K. (2011). Academic cohorts: Benefits and drawbacks of being a member of a community of learners. Education, 131(3), 497-504.

Lencioni, P. (2002). Five dysfunctions of a team: A leadership fable. San Francisco, CA: Jossey-Bass.

Levi, D. (2014). Group dynamics for teams (4th ed.). Thousand Oaks, CA: SAGE.

Lin, C. P., Shao, Y. J., Wong, L. H., Li, Y. J., \& Niramitranon, J. (2011). The impact of using synchronous collaborative virtual tangram in children's geometric. Turkish Online Journal of Educational Technology, 10(2), 250-258.

Longworth, R.C. (2008). Caught in the Middle: America's Heartland in the Age of Globalism. New York: Bloomsbury.

Marzano, R. J., Pickering, D., \& Pollock, J. E. (2001). Classroom instruction that works: Research-based strategies for increasing student achievement. Alexandria, VA: Association for Supervision and Curriculum Development.

Merriam. S. B., \& Bierema, L. L. (2014). Adult learning: Linking theory and practice. San Francisco, CA: Jossey-Bass.

Merriam, S. B., \& Tisdell, E. J. (2016). Qualitative research: A guide to design and implementation (4th ed.). San Francisco, CA: Joseey-Bass. 
ADMINISTRATORS' PERCEPTIONS OF TEACHER EFFECTIVENESS

Mihelic, K.K., Lipicnik, B., \& Tekavcic, M. (2010). Ethical leadership. International Journal of Management and Informational Systems, 14(5), 31-41.

DOI: 10.19030/ijmis.v14i5.11

Mintzberg, H. (1979). The five basic parts of the organization. In Shafritz, J. M., Ott, S. J., \& Jang, Y. S. (2005). Classics of organizational theory (6th ed.) (pp. 61-72). Belmont, CA: Wadsworth.

MoASSP. (2018) Missouri association of secondary school principals. Retrieved on July 20, 2018, from http://moassp.org/index.php

Newcomer, K.E., Hatry, H.P., \& Wholey, J.S. (2015). Handbook of practical program evaluation ( ${ }^{\text {th }}$ ed.). Hoboken, NJ: Jossey-Bass.

Nicosia, M. (2017). Weigh in on new report's findings tying gap to prosperity. T74 Media. Retrieved from https://www.the74million.org/article/solving-the-ruraleducation-gap-experts-weigh-in-on-new-reports-findings-tying-gap-to-prosperity/

Northouse, P.G. (2016). Leadership: Theory and practice ( $7^{\text {th }}$ ed.). Thousand Oaks, CA: SAGE.

Rosen, Y., \& Manny-Ikan, E. (2011). The social promise of the Time to Know program. Journal of Interactive Online Learning, 10(3), 150-161.

Rutherford Learning Group (2016). The Artisan Teacher. Retrieved at http://www. rutherfordlg.com/

Schein, E. H. (1993/2005). Defining organizational culture. In J. M. Shafritz, J. S. Ott, \& Y. S. Jang (Eds.), Classics of organizational theory (6th ed., pp.360-367). Belmont, CA: Wadsworth. (Reprinted from Organizational culture and leadership, pp. 3-15, 1993, San Francisco, CA: John Wiley \& Sons). 


\section{ADMINISTRATORS’ PERCEPTIONS OF TEACHER EFFECTIVENESS}

Seidman, I. (2013). Interviewing as Qualitative Research (4th ed). New York, NY: Teachers College Press.

Selznick, P. (1948). Foundations of the theory of organization. In D. Tatom (Ed.), Classics of organization theory (pp. 125-134). Belmont, CA: Wadsworth, Cengage Learning.

Shapley, K. S., Sheehan, D., Maloney, C., \& Caranikas-Walker, F. (2010). Evaluating the implementation fidelity of technology immersion and its relationship with student achievement. Journal of Technology, Learning, and Assessment, 9(4), 1-69.

Shoulders, T.L., \& Krei, M.S. (2015). Rural high school teachers' self-efficacy in student engagement, instructional strategies, and classroom management. American Secondary Education, 44(1), 50-61.

Smith, I. \& Addison, C. (2013). The 'new' school leader: Training instructional leaders for a new generation of teachers and learners. Academy of Educational Leadership Journal, 17, 135-140.

Teach: Make a Difference. (2017). Rural Schools. [website] Retrieved at https://teach.com/where/types-of-schools/other-types-of-schools/rural-schools/

Thorpe, R. (2014). Sustaining the teaching profession. New England Journal of Public Policy, 26(1), 1-16.

Tirozzi, G.N. (2001). The artistry of leadership: The evolving role of the secondary school principal. Phi Delta Kappan, 82(6), 434-439.

Waters, T., Marzano, R.J., \& McNulty, B. (2003). Balanced leadership: What 30 years of research tells us about the effect of leadership on student achievement (Working Paper). Retrieved from the California Commission on Teacher Credentialing 


\section{ADMINISTRATORS' PERCEPTIONS OF TEACHER EFFECTIVENESS}

website: https://www.ctc.ca.gov/docs/default-source/educatorprep/asc/5031rr_balanced leadership.pdf

Whitaker, T. (2012). What great teachers do differently: Seventeen things that matter most. Larchmont, NY: Eye on Education.

Wong, H. K., \& Wong, R. T. (1998). The First Days of School: How to Be an Effective Teacher.

Wygal, D. E., \& Stout, D. E. (2015). Shining a light on effective teaching best practices: Survey findings from award-winning accounting educators. Issues In Accounting Education, 30(3), 173-205. Doi: 10.2308/iace-51038

Zhao, Y. (2015). A world at risk: An imperative for a paradigm shift to cultivate $21^{\text {st }}$ century learners. Society, 52(2), 129-135. Doi: 10.1007/s12115-015-9872-8 


\section{ADMINISTRATORS’ PERCEPTIONS OF TEACHER EFFECTIVENESS}

\section{VITA}

The author of this study, Sarah Barmann-Smith, began her career in Education in 2005. Sarah is a fourth-generation educator and knew from a young age she wanted to work with others and have a positive impact serving people. Sarah is dedicated to the profession and has a passion for helping others learn and continued growth and learning herself. She graduated from Northwest Missouri State University in 2005 with an undergraduate degree in Secondary English Education and earned her Masters of Science in Educational Leadership in 2012.

Sarah taught high school English and middle school Reading in the Albany R-III School District from 2005-2006. She moved to Liberty, MO and taught English at Fort Osage High School for eight years. During that time, she was the K-12 ELA Curriculum Facilitator, ELA department chair, involved in planning professional development, received the MVP teacher award, and coached debate/forensics and cheerleading.

Sarah joined the administrative team at the Albany R-III School District in 2014, serving as the principal at Virginia E. George Elementary School for two years and then took on the role as the principal of Albany Middle/High School where she is currently serving. She has two children enrolled in the district where she serves and a husband who is a proud Warrior alumni. Sarah entered the Educational Leadership and Policy Analysis doctoral program with Cohort 10 through the University of Missouri Statewide Cooperative Program. 